University of Wollongong

Research Online

Faculty of Engineering and Information

Faculty of Engineering and Information

Sciences - Papers: Part B

Sciences

2017

\title{
Ultimate Tilt-Bearing Capacity of Bolted Connections in Cold-Reduced Steel Sheets
}

Lip H. Teh

University of Wollongong, Iteh@uow.edu.au

Mehmet Eren Uz

University of Wollongong, meuz@uow.edu.au

Follow this and additional works at: https://ro.uow.edu.au/eispapers1

Part of the Engineering Commons, and the Science and Technology Studies Commons

Research Online is the open access institutional repository for the University of Wollongong. For further information contact the UOW Library: research-pubs@uow.edu.au 


\title{
Ultimate Tilt-Bearing Capacity of Bolted Connections in Cold-Reduced Steel Sheets
}

\author{
Abstract \\ This paper examines the accuracy of design equations specified in the North American, European, and \\ Australasian codes for cold-formed steel structures in determining the ultimate tilt-bearing capacity of \\ single-shear bolted connections without washers in flat steel sheets. It points out that all the code \\ equations do not properly distinguish the tilt-bearing failure mode from the conventional bearing failure \\ mode. While the latter takes place downstream of the bolt, the former takes place upstream. Unlike the \\ conventional bearing capacity, the tilt-bearing capacity is affected by the width of the connected sheet \\ and does not vary linearly with either the sheet thickness or the bolt diameter. Furthermore, it is not \\ affected by material ductility. Based on the test results of 156 specimens composed of G2 and G450 \\ sheet steels having various dimensional configurations, this paper proposes a design equation that is \\ dimensionally consistent and that is considerably more accurate than all the code equations. The \\ proposed equation was also verified against single-shear single-row bolted connections tested by \\ independent researchers which failed in the tilt-bearing mode. The verified thicknesses ranged from 0.92 \\ to $3.0 \mathrm{~mm}$, and the bolt diameters ranged from 6.4 to $16 \mathrm{~mm}$. An additional finding is that the tilt-bearing \\ capacity is not significantly affected by the orientation of the bolt head or nut. A resistance factor of 0.75 \\ is recommended for use with the proposed equation for determining the tilt-bearing capacity of single \\ shear single-row bolted connections in cold-reduced steel sheets.

\section{Disciplines} \\ Engineering | Science and Technology Studies

\section{Publication Details} \\ Teh, L. H. \& Uz, M. E. (2017). Ultimate Tilt-Bearing Capacity of Bolted Connections in Cold-Reduced Steel \\ Sheets. Journal Of Structural Engineering, 143 (4), 04016206-1-04016206-12.
}


4 Abstract:
5

6

7

\title{
Ultimate Tilt Bearing Capacity of Bolted Connections in Cold-Reduced
}

\author{
Steel Sheets
}

\author{
Lip H. Teh ${ }^{1}$ M.ASCE and Mehmet E. Uz ${ }^{2}$
}

\section{Abstract:}

This paper examines the accuracy of design equations specified in the North American,

European and Australasian codes for cold-formed steel structures in determining the ultimate tilt bearing capacity of single-shear bolted connections without washers in flat steel sheets. It points out that all the code equations do not properly distinguish the tilt bearing failure mode from the conventional bearing failure mode. While the latter takes place downstream of the bolt, the former takes place upstream. Unlike the conventional bearing capacity, the tilt bearing capacity is affected by the width of the connected sheet and does not vary linearly 2 with either the sheet thickness or the bolt diameter. Furthermore, it is not affected by material 3 ductility. Based on the test results of 156 specimens composed of G2 and G450 sheet steels 4 having various dimensional configurations, this paper proposes a design equation that is 5 dimensionally consistent and that is considerably more accurate than all the code equations. The proposed equation was also verified against single-shear single-row bolted connections tested by independent researchers which failed in the tilt bearing mode. The verified thicknesses ranged from $0.92 \mathrm{~mm}$ to $3.0 \mathrm{~mm}$, and the bolt diameters ranged from $6.4 \mathrm{~mm}$ to $916 \mathrm{~mm}$. An additional finding is that the tilt bearing capacity is not significantly affected by 20 the orientation of the bolt head or nut. A resistance factor of 0.75 is recommended for use 1 with the proposed equation for determining the tilt bearing capacity of single shear single2 row bolted connections in cold-reduced steel sheets.

Author keywords: bolted connections, bearing strength, bolt punching, cold-formed steel, connection capacity, connection curling, single-shear bolted connection, tilt bearing

\footnotetext{
${ }^{1}$ Associate Professor, School of Civil, Mining \& Environmental Engineering, University Of Wollongong, Wollongong, NSW 2500, AUSTRALIA.

${ }^{2}$ Lecturer, Department of Civil Engineering, Adnan Menderes University, Aydin, PK:09100, TURKEY. Formerly Associate Research Fellow, ARC Research Hub for Australian Steel Manufacturing, Wollongong, NSW 2500, AUSTRALIA.
} 


\section{Introduction}

The ultimate bearing capacity of a bolted connection in cold-formed steel sheet is specified in Section E3.3.1 of the North American Specification for the Design of Cold-formed Steel Structural Members 2012 (AISI 2012), in Table 8.4 of the European code EN-1993-1-3:2006 (ECS 2006), and in Clause 5.3.4.2 of the Australasian standard AS/NZS 4600:2005 (SA/SNZ 2005). No fundamental distinction is made in any of the design codes between a double-shear and a single-shear connection, although the North American and the Australasian codes employ modification factors that are equal to 1.33 for the inside sheet of a double-shear connection and 0.75 for a single-shear connection without washers. However, the conventional bearing failure mode typical of the inside sheet of a double-shear connection has a fundamentally different mechanism from the tilt bearing failure mode that may be experienced by a single-shear connection without washers, as evident from Figure 1.

It can be seen that the conventional bearing failure shown in Figure 1(a) occurred on the downstream side of the bolt hole (i.e. in the direction of bolt displacement), while the tilt bearing failure of the single-shear single-bolt connection without washers in Figure 1(b) was due to the bolt head (and nut) punching through the sheet on the upstream side during tilting under eccentric loading. Figure 2 shows that, in a tilt bearing failure, fracture takes place on the upstream side of the bolt hole, and not on the downstream side.

Another distinguishing feature of the tilt bearing failure mode is curling of the single-shear connected sheets, as shown in Figure 3. The curling, which can be observed long before the single-shear connection reaches the ultimate load, and which facilitates bolt tilting, is essentially bending of the sheet under eccentric loading. If curling is absent (or restrained), then it will be more difficult for the bolt head or nut to punch through the connected sheet on the upstream side. This fact indicates that the tilt bearing capacity of a bolted connection does 
not necessarily vary linearly with the sheet thickness, and that the sheet width is a factor resisting the tilt bearing failure.

It should be noted that the present connections, which are without washers, are not comparable to the single-shear connections tested by Bryan (1993). The presence of washers in the specimens of Bryan (1993) ensured that failures occurred on the downstream side of the bolt hole, which could even be in the form of shear-out (or tear-out). Likewise, the bearing failures of the single-shear connections tested by Yan \& Young (2011) took place on the downstream side due to the use of washers and clips that prevented independent curling of the connected sheets. The finite element models of Yan \& Young (2012), on the other hand, were prevented from out-of-plane displacements in the connection region.

When no washer nor clip is used for a single-shear bolted connection in thin steel sheet, there is another failure mode that was associated by some researchers with tilting and bearing. The failure mode is depicted in Figure 4, and was experienced by many of the specimens tested by Carril et al. (1994) and Casafont et al. (2006). Such a failure mode was called "localised tearing” by Rogers \& Hancock (2000), who used clips and observed that this failure mode only took place in the more ductile mild sheet steels. It should be noted that the localised tearing mode may take place with or without washers/clips. This failure mode may also happen to a serial bolted connection, as shown by Rogers \& Hancock (2000), and was in the past mistaken to be the net section tension fracture mode as discussed by LaBoube (1988) and Rogers \& Hancock (2000). The localised tearing mode is outside the scope of this paper.

The authors did not detect evidence of tilt bearing failures as studied in this paper among the specimens tested by Wallace \& Schuster (2001). Figure 6(a) of Wallace \& Schuster (2001) shows a bearing failure on the downstream side of the bolt hole of a specimen without washers despite the presence of curling, as also described in their report. This failure mode is 
similar to that shown in the top right photo of Fig. 8 of Talja \& Torkar (2014), which shows the failure of a single-shear screwed connection with an integrated washer. Yu \& Mosby (1981), who tested single-shear bolted connections in thin sheets, did not discuss the tilt bearing failure mode shown in Figures 1(b) and 2.

Rogers \& Hancock (2000) did not describe the failure mode that is due to the bolt head and nut punching through the connected sheets on the upstream side of the respective bolt holes during tilting. However, they mentioned the "bearing with end curling" mode, which was associated with fracture on the downstream side of the bolt hole. Unlike the tilt bearing failure mode studied in this paper, the bearing with end curling mode can happen to bolted connections with washers, and without bolt tilting as depicted in Figure 5.

The tilt bearing failure mode has not been described in any design code or guidelines either. The North American and the European guidelines on the testing of sheet steel connections (AISI 2008, ECCS 2009) describe five failure modes including the so-called "tilting and pullout failure” mode, but do not mention the tilt bearing failure shown in Figures 1(b) and 2. Likewise, Yu \& Panyanouvong (2013) depicted four failure modes for single-shear bolted connections, but did not include the tilt bearing failure mode studied in this paper.

This paper presents the first ever systematic study on the tilt bearing capacities of bolted connections, which are due to the bolt head and nut punching through the connected sheets on the upstream side of the respective bolt holes during tilting, an example of which is shown in Figure 1(b). The failure mode has been observed for single-shear single-row bolted connections without washers in cold-reduced steel sheets only, which are often used in bracing applications of light gauge cold-formed steel frames. The paper details how a nonlinear empirical equation for the ultimate tilt bearing capacity can be derived methodically without losing dimensional consistency. The design equation will be formulated 
based on the results of 156 G2 and G450 sheet steel specimens having various dimensional configurations tested in the present work, and verified against independent test results of other researchers (Casafont et al. 2006, Yu \& Sheerah 2008, Hoang et al. 2013) where the single-shear single-row bolted connection specimens are known to have failed by tilt bearing.

Interested readers may consult Teh \& Uz (2014) for the conventional bearing failure mode, Teh \& Gilbert (2012) for the net section tension fracture mode, Teh \& Clements (2012) for the block shear failure mode, and Teh \& Uz (2015) for the shear-out failure mode. The definitions may differ from those used by some other researchers, and the authors believe that the definitions by Teh and co-workers are correct and consistent.

Bolt hole deformation at service load is not a concern in this paper. The tilt bearing capacity of a specimen is defined as the maximum test load achievable.

\section{Equations for bearing capacity of single-shear bolted connection}

Section E3.3.1 of the North American Specification for the Design of Cold-formed Steel Structural Members 2012 (AISI 2012) specifies the bearing capacity per bolt of a single-shear bolted connection without washers to be

$$
P_{b}=0.75 C d t F_{u}
$$

in which $d$ is the bolt diameter, $t$ is the sheet thickness and $F_{\mathrm{u}}$ is the material tensile strength. The bearing factor $C$ depends on the ratio of the bolt diameter $d$ to the sheet thickness $t$, as shown in Table 1. It may be noted that a ratio $d / t$ greater than 10 is rare in practice.

According to the North American specification (AISI 2012), the "modification factor" of 0.75 in Equation (1) differentiates a single-shear connection from a double-shear one (1.33), and accounts for the absence of washers (1.00). These values were obtained by Wallace \& 
Schuster (2002) through statistical analysis of the test results of Wallace \& Schuster (2001).

All other variables in Equation (1) are the same between the various connection configurations despite the very different mechanisms evident in Figure 1 between the tilt bearing failure possible for single-shear single-row bolted connections without washers and the conventional bearing failure typical of double-shear connections or single-shear connections with washers. However, it is most unlikely that the different failure mechanisms can be adequately accounted for using only the modification factors defined in Section E3.3.1 of the specification (AISI 2012).

It can be seen from the statistical results of Wallace \& Schuster (2002) that Equation (1) leads to a large coefficient of variation equal to 0.151 , meaning that on average the error is about $15 \%$ on either side of conservatism. One reason is already mentioned in the preceding paragraph. Another possible reason is that some of the analysed specimens failed in the tilt bearing mode shown in Figure 1(b) while others failed in bearing on the downstream side of the bolt hole, as shown in Figure 6(a) of Wallace \& Schuster (2001).

In any case, the Australasian cold-formed steel structures standard (SA/SNZ 2005) adopts Equation (1) for a single-shear bolted connection without washers. On the other hand, the European code EN-1993-1-3:2006 (ECS 2006) does not make a distinction between single and double shear connections, and does not consider the benefit of washers. For the specimens tested in the present work, in which the end distance was invariably more than 3 times the bolt diameter, the European code specifies the bearing strength per bolt to be

$$
P_{b}=2.5 k_{t} d t F_{u}
$$

in which the variable $k_{\mathrm{t}}$ is equal to unity for sheet thicknesses greater than $1.25 \mathrm{~mm}$, otherwise it is 


$$
k_{t}=\frac{0.8 t+1.5}{2.5} ; \quad 0.75 \mathrm{~mm} \leq t \leq 1.25 \mathrm{~mm}
$$

144 For Equation (3) to be valid (not necessarily accurate), not only the metric system must be used, but the sheet thickness $t$ must also be measured in millimetres since the two constants are dimensionless. Such a dimensionally inconsistent equation should be avoided as much as possible since it is prone to errors in design calculations.

Equations (1) and (2) imply that the "bearing capacity" of a single-shear single-row bolted connection varies linearly with the sheet thickness and the bolt diameter, in the same manner as that of a double-shear connection. However, such simple relationships are unlikely to hold when the failure is due to the bolt head and nut punching through the connected sheets on the upstream side of the respective bolt holes during tilting. Furthermore, the sheet width $W$ is likely to influence the tilt bearing capacity as the resistance to curling and therefore bolt tilting increases with increasing width, yet this parameter is absent in both code equations.

In the present work, the tilt bearing capacity per bolt of a single-shear single-row bolted connection is expressed as

$$
P_{b}=C_{\mathrm{tb}} d^{b} t^{a} W_{n}^{c} F_{u}
$$

in which $W_{\mathrm{n}}$ is the sheet width that is net of the bolt hole diameter. The geometric variables are defined in Figure 6. For single-row bolted connections having more than one bolt, the net sheet width $W_{\mathrm{n}}$ is equal to the total net sheet width divided by the number of bolts.

The ultimate tilt bearing coefficient $C_{\mathrm{tb}}$ and the exponential terms $a$ through $c$ would be determined through analyses of the present test results, and verified against independent test results of other researchers whose specimens are known to have failed in tilt bearing due to 
the bolt head punching through the connected sheet on the upstream side of the bolt hole (Casafont et al. 2006, Yu \& Sheerah 2008, Hoang et al. 2013).

In order to ensure dimensional consistency, the sum of the exponential terms $a, b$ and $c$ must be equal to 2. Since the least dominant geometric variable on the tilt bearing capacity is the net sheet width $W_{\mathrm{n}}$, which is absent in the code equations, the exponential term $c$ is determined solely as a function of $a$ and $b$

$$
c=2-(a+b)
$$

\section{Test materials}

The G450 and G2 sheet steel materials used in the present laboratory tests, which have trade names GALVASPAN ${ }^{\circledR}$ and GALVABOND ${ }^{\circledR}$, respectively, were manufactured and supplied by Bluescope Steel Port Kembla Steelworks, Australia. G2 sheet steel is classified as a formability grade, while G450 sheet steel is a structural grade (SA 2011).

The average yield stresses $F_{y}$, tensile strengths $F_{u}$ and elongations at fracture over $15 \mathrm{~mm}, 25$ $\mathrm{mm}$ and $50 \mathrm{~mm}$ gauge lengths $\varepsilon_{15}, \varepsilon_{25}$ and $\varepsilon_{50}$, and uniform elongation outside the fracture $\varepsilon_{\mathrm{uo}}$ of the steel materials as obtained from $12.5 \mathrm{~mm}$ wide tension coupons are shown in Tables 2 and 3 for the G450 and G2 sheet steels, respectively. The variable $t_{\text {base }}$ denotes the base metal thickness without the coating. Tensile loadings of all coupons and bolted connection specimens are in the rolling direction of the sheet steel, as required for structural grade sheet steels (SA 2011). The tension coupon tests were conducted at a constant stroke rate of 1 $\mathrm{mm} /$ minute resulting in a strain rate of about $2 \times 10^{-4}$ per second prior to necking.

Tables 2 and 3 show that the G2 sheet steel is considerably more ductile than the G450 sheet steel. The 1.9-mm and 2.4-mm G450 sheet steels just meet the requirements for being used without restriction according to Section A2.3.1 of the North American specification (AISI 
2012), while the 1.5-mm and 3.0-mm ones marginally fail them. However, G450 sheet steel is a structural grade covered by the Australasian standard (SA/SNZ 2005) for which the nominal tensile strength and yield stress may be fully utilised in structural design calculations (Hancock 2007).

\section{Specimen configurations and test arrangements}

Almost all specimens tested in the present work were single-shear single bolted connections, as depicted in Figure 3. The distance between each bolt and the downstream end was at least $50 \mathrm{~mm}$ to prevent the shear-out failure mode. Each specimen was only lightly tightened by hand.

For the purpose of determining the relationship between the sheet thickness and the tilt bearing capacity, the present work tested fifty seven G450 sheet steel specimens having nominal thicknesses of 1.5, 1.9, 2.4 and $3.0 \mathrm{~mm}$. The resulting equation would be verified against the test results of $\mathrm{Yu} \&$ Sheerah (2008) involving $0.92 \mathrm{~mm}$ Grade 33 and $1.12 \mathrm{~mm}$ Grade 50 sheet steels.

In order to ascertain the effect of sheet width, for almost every thickness of the G450 sheet steels, the widths were 50, 60, 70, 75, 100 and $120 \mathrm{~mm}$. These values represent the range that may be covered by one bolt in cold-formed steel constructions. The 120 -mm wide specimens with 12-mm bolt represent a bolt spacing of 10 times the bolt diameter, which is unlikely to be exceeded in practice. The derived equation would be verified against the test results of $\mathrm{Yu}$ \& Sheerah (2008) involving a ratio of sheet width to bolt diameter W/d close to 16.

Two bolt sizes commonly used for structural connections in G450 sheet steels, 12 and 16 $\mathrm{mm}$, were used in the present tests, resulting in the ratio of bolt diameter to sheet thickness $d / t$ ranging from 4.0 to 10.7. The proposed equation would be verified against the test results of 
210 Yu \& Sheerah (2008) involving $6.4 \mathrm{~mm}$ bolts, and those of Casafont et al. (2006) and Hoang

211 et al. (2013) involving $8 \mathrm{~mm}$ bolts.

212 According to Section E3a of the North American specification (AISI 2012), the standard hole

213 diameter shall not be more than $1 \mathrm{~mm}$ greater than the bolt diameter for bolt sizes up to 13

$214 \mathrm{~mm}$, or more than $2 \mathrm{~mm}$ greater than the bolt diameter for bolt sizes over $13 \mathrm{~mm}$. Similar

215 clearances are specified in Clause 5.3.1 of the Australasian standard (SA/SNZ 2005), except

216 that the threshold bolt size is $12 \mathrm{~mm}$. The specimens of Yu \& Sheerah (2008) which had

217 significantly larger hole clearances, i.e. oversized holes, are not included in the present

218 verification unless commensurately oversized bolt heads were used.

219 The fifty seven specimens whose results would be used to determine the relationships

220 between the tilt bearing capacity and each of the three geometric variables had a nominal bolt

221 hole clearance of $2 \mathrm{~mm}$, the absolute maximum allowed by the codes (AISI 2012, SA/SNZ

222 2005). The effect of smaller bolt hole clearance would be investigated by testing twenty nine

223 G450 and thirty two G2 specimens having $1 \mathrm{~mm}$ clearance only.

224 A total of sixty four specimens composed of G2 sheet steel, which has very different ductility

225 characteristics from G450 sheet steel as evident from Tables 2 and 3, would be tested in light

226 of the finding of Teh \& Uz (2014) regarding the effect of material ductility on the bearing

227 capacity of double-shear bolted connections. Importantly, the G2 specimens also provided an

228 opportunity to investigate the effect of the orientation of bolt head and nut on the tilt bearing

229 capacity. The two orientations are shown schematically in Figure 7, with actual samples

230 shown in Figure 8.

231 The measured dimensions of the 12-mm and 16-mm bolt heads are shown in Figure 9. These

232 parameters are important since it is the bolt head and nut that punch through the sheet. 
Supplementing the one hundred fifty single-bolt connection specimens tested in the present work, a total of six single-shear single-row double bolted connection specimens were also tested. An example is shown in Figure 10.

For all specimens, the two connected sheets were nominally identical to each other. This arrangement means that the equation derived in the present work for determining the ultimate tilt bearing capacity represents the lower bound when the equation is applied to the weakest sheet.

\section{Mechanism of a tilt bearing failure}

The properties of the specimens cited in the following paragraphs are given in Tables 4 through 8 discussed in the next section, but they are not essential to the discussions in this section. The label designations of the specimens mainly followed the order of testing.

Figure 11 shows a bolt head punching through the bolt hole of Specimen ES34, which fractured on the upstream side as can be seen in the photograph when examined closely. The load-displacement graph of the specimen is plotted in Figure 12, which shows a little kink associated with the fracture before the applied load gradually dropped. It is therefore tempting to conclude that the ultimate tilt bearing capacity of a bolted connection is reached whenever fracture takes place on the upstream side of either bolt hole, in a similar manner that the net section tension capacity is associated with fracture of the weakest sheet. However, Figure 12 does not show the typical load-displacement behaviour of the specimens tested in the present work.

Figure 13 demonstrates that Specimen ES37a, shown in Figure 1(b), was able to recover after the initial drop in the applied load following fracture on the upstream side of the bolt hole as the bolt head punched through. The specimen reached a second peak load before its load- 
carrying capacity definitely decreased. In fact, such a behaviour is not uncommon among the tested specimens as shown in Figure 13 for Specimen ES37b and in Figure 14 for Specimens ES46a, ES49b and YK21. It appears that, for these specimens, the ultimate load capacity was only reached after fractures took place on the upstream side of both bolt holes (both sheets).

Unlike other failure modes such as the net section tension fracture mode and the block shear failure mode, a fracture on the upstream side of only one bolt hole (one sheet) does not necessarily mean that the connection has reached its maximum resistance to bolt tilting under the eccentric loading (see Figure 3 for illustration). The other, still intact sheet is capable of providing further resistance to bolt tilting, so the connection is able to carry increased loading until fracture takes place in the second sheet (it should be noted that there is no fracture on the downstream side of either bolt hole).

In any case, it is evident that the sheet width must affect the ultimate tilt bearing capacity of a single-shear single-row bolted connection since the wider the sheet, the greater its available resistance to curling and therefore to tilting. This assertion is supported by the test results presented in Tables 4 through 9 discussed in the next section.

It is noteworthy that some load-displacement graphs do not exhibit a noticeable kink, as shown in Figure 13 for Specimen ES37b, and in Figure 15 for Specimens ES12 and YK1, the latter two only experiencing one peak load each like Specimen ES34 discussed previously. Another interesting thing is that the three specimens plotted in Figure 14 did not have significantly different initial response despite their different geometry, in contrast to the comparison between Specimens ES12 and YK1 in Figure 15. Advanced finite element analysis is required to investigate the issues thoroughly.

\section{Exponential terms $\boldsymbol{a}, \boldsymbol{b}$ and $c$}


279 Tables 4 and 5 lists the geometric dimensions and ultimate test loads of G450 specimens that 280 had a nominal bolt hole clearance of $2 \mathrm{~mm}$, for 12-mm and 16-mm bolts, respectively. For 281 legibility, only the nominal values of the geometric variables are shown in the tables. 282 However, for calculation purposes, the measured values and the base metal thicknesses listed 283 in Tables 2 and 3 were used. An empty cell in a table indicates that the data in the above cell applies.

The variable $P_{\mathrm{t}}$ in the tables denotes the ultimate test load obtained in the experimental program, while $P_{\mathrm{p}}$ is the tilt bearing capacity predicted by the equations. The ratio $P_{\mathrm{t}} / P_{\mathrm{p}}$ is called the professional factor. It can be seen that Equations (1) and (2), which are premised on the conventional bearing failure on the downstream side of the bolt, considerably overestimated the ultimate tilt bearing capacity. Everything else remaining the same, the overestimations decrease with increasing sheet thicknesses. This observation indicates that the tilt bearing capacity increases exponentially with the sheet thickness.

The variations of the tilt bearing capacity with the sheet thickness were checked against 12 groups of specimens across the nominal thicknesses ranging from $1.5 \mathrm{~mm}$ to $3.0 \mathrm{~mm}$ in each group, as shown in Tables 4 and 5. The only (nominal) geometric variable in each group is the sheet thickness $t$, with the bolt diameter $d$ and the sheet width $W$ remaining constant. In most groups, the reference (nominal) thickness is $1.5 \mathrm{~mm}$. The normalised capacity ratio $r_{\text {th }}$ shown in the tables were calculated from

$$
r_{\text {th }}=\frac{P_{t} F_{\text {uree }} t_{\text {ref }}}{P_{\text {tref }} F_{u} t}
$$

An entry "Ref" in Tables 4 or 5 indicates that the specimen is the reference specimen for the group of specimens having the same bolt diameter and the same nominal width $W$, whose properties and ultimate test load are identified by the subscript “ref” in Equation (6). 
302 As can be seen in Tables 4 and 5, some configurations were tested twice, and the specimens were denoted by the prefix “a” or "b” in their respective labels. For such specimens, only their average values were used in the calculations.

Figure 16 plots the normalised capacity ratios $r_{\text {th }}$ for three groups of specimens found in Tables $4(d=12 \mathrm{~mm})$ and $5(d=16 \mathrm{~mm})$ that covered the four nominal thicknesses. If the actual tilt bearing capacity varied linearly with the sheet thickness, then the ratios $r_{\text {th }}$ would be constant at unity across the different thicknesses. However, as shown in the figure, the normalised capacity ratios increased with the sheet thicknesses, which means that the tilt bearing capacity increases more rapidly than the sheet thickness.

$$
r_{\text {th }}=\left(t / t_{r e f}\right)^{a-1}
$$

313 In order to avoid a decimal exponential term in Equation (4) if feasible, the exponential term $a$ is taken to have the following form

$$
a=1+i / j
$$

in which $i$ and $j$ are positive integers. The measured base thicknesses listed in Tables 2 and 3 were used in determining the exponential term $a$.

Based on the test results shown in Tables 4 and 5, it was found that using $a=4 / 3$ simulated the relationship between the tilt bearing capacity and the sheet thickness quite well. It can be shown that the resulting mean "professional factor" for the ratios $r_{\text {th }}$ is 1.02 with a coefficient of variation equal to 0.062 . 
322 The relationship between the tilt bearing capacity and the bolt diameter was investigated next.

323 Strictly speaking, the relevant parameter is the bolt head size rather than the bolt shank

324 diameter since it is the bolt head (and nut) that punches through the connected sheet.

325 However, as can be computed using the data given in Figure 9, for the 12-mm and 16-mm

326 bolts used in the present work, the ratio of the bolt shank diameters is the same as that of the

327 bolt head sizes, so it does not matter which parameter is used for determining the relationship

328 between the tilt bearing capacity and the bolt diameter. However, in practice it is common to use the bolt shank (nominal) diameter rather than the bolt head size in designing a bolted connection.

The variable $r_{\mathrm{d}}$ in Table 5 denotes the ratio between the ultimate test load of a $16-\mathrm{mm}$ bolt specimen and that of the corresponding 12-mm bolt specimen, the latter given in Table 4 . The average test value of the ratio $r_{\mathrm{d}}$ is 1.16 , with a coefficient of variation equal to 0.065 . It was found that the use of an exponential term $b$ in Equation (4) equal to $1 / 2$ would give a ratio of 1.15. The exponential term $b$ is therefore taken to be $1 / 2$, meaning that the tilt bearing capacity varies with the square root of the bolt diameter.

Incidentally, the use of $b=1 / 2$ is consistent with a limiting equation for the "tilting and hole bearing” capacity of a screwed connection specified in Clause 5.4.2.3 of the Australasian cold-formed steel structures standard (SA/SNZ 2005). This clause corresponds to Section E4.3.1 of the North American specification (AISI 2012), which uses the term "shear strength limited by tilting and bearing”. It may be noted that the limiting equation has the strength of a screwed connection varying with the sheet thickness at the power of $3 / 2$. The sheet width is not a parameter in the specification equation.

Having determined the exponential terms $a$ and $b$ to be $4 / 3$ and $1 / 2$, respectively, the exponential term $c$ was computed from Equation (5) to be $1 / 6$. 
346 Ultimate tilt bearing coefficient

347 Table 6 lists the geometric dimensions and ultimate test loads of the G450 specimens which

348 had a nominal bolt hole clearance of $1 \mathrm{~mm}$. It was found that the tighter hole clearance 349 increased the ultimate tilt bearing capacity by about 5\% only on average, justifying the use of 350 one tilt bearing coefficient $C_{\mathrm{tb}}$ common to all bolt holes having clearances up to the 351 maximum of $2 \mathrm{~mm}$ allowed by the codes (AISI 2012, SA/SNZ 2005).

352 Tables 7 and 8 list the geometric dimensions and ultimate test loads of G2 specimens that had 353 nominal bolt hole clearances of $2 \mathrm{~mm}$ and $1 \mathrm{~mm}$, respectively. By comparing the professional 354 factors in these tables against those in Tables 4 through 6, it can be concluded that the significantly different levels of material ductility between G2 and G450 sheet steels, as evident from Tables 2 and 3, did not affect the tilt bearing capacities. This conclusion supports the assertion that the tilt bearing failure mode shown in Figure 1(b) has a fundamentally distinct mechanism from the conventional bearing failure mode shown in Figure 1(a), since the latter is significantly affected by material ductility (Teh \& Uz 2014).

The results shown in Tables 7 and 8 also indicate that the orientations of the bolt head and nut did not have significant effect on the ultimate tilt bearing capacity, although there was some $5 \%$ difference on average for the specimens having a nominal hole clearance of $2 \mathrm{~mm}$. For the specimens having a nominal hole clearance of $1 \mathrm{~mm}$, there were no consistent differences in the tilt bearing capacities. This finding avoids a potential complication for the design equation. The orientations I and II specified in the tables are shown in Figures 7 and 8. It may be noted that the specimens listed in Tables 4 through 6 had random orientations.

Having established that variations in bolt hole clearances (within code limits), material ductility, and bolt head/nut orientation do not have meaningful effects on the ultimate tilt 
369

370

371

372

373

374

375

376

377

379

380

381

382

383

384

385

386

387

388

389 390

bearing capacity of single-shear single-row bolted connections, the ultimate tilt bearing coefficient $C_{\mathrm{tb}}$ in Equation (4) was determined to be 2.65 (rounded to the nearest 0.05 ) based on the ultimate test loads of 150 specimens listed in Tables 4 through 8 and the exponential terms $a, b$ and $c$ computed in the preceding section. Equation (4) therefore becomes

$$
P_{b}=2.65 d^{1 / 2} t^{4 / 3} W_{n}^{1 / 6} F_{u}
$$

\section{Verifications of the proposed equation}

The professional factors of Equation (9) for the present test specimens are given in Tables 4 through 9. Table 9 contains the results of single-shear single-row double bolted connection specimens tested to verify the use of Equation (9) where the variable $W_{\mathrm{n}}$ is equal to the total net sheet width divided by two.

Equation (9) was also checked against the test results of independent researchers where the specimens failed by tilt bearing due to the bolt head punching through the connected sheet on the upstream side of the bolt hole, and where the nominal hole diameter clearance did not exceed 2 mm. Yu \& Sheerah (2008) tested 12 such specimens composed of Grade 33 and Grade 50 sheet steels with a diameter clearance of $1.6 \mathrm{~mm}$ on 1/4-inch A307 bolt, the results of which are shown in the first twelve rows of Table 10.

Table 10 shows that Equations (1) and (9) give similar professional factors for the specimens tested by Yu \& Sheerah (2008). In any case, it can be seen that Equation (9) is reasonably accurate if somewhat conservative for the $0.92 \mathrm{~mm}$ thick specimens, each of which was connected by a $6.4 \mathrm{~mm}$ bolt. It is quite accurate for the $1.12 \mathrm{~mm}$ thick specimens.

Casafont et al. (2006) tested single-shear single-row bolted connections having two bolts each, similar to the specimen shown in Figure 10. From the photographs provided in their 
391

392

393

394

395

396

397

398

399

400

401

402

403

404

405

406

407

408

409

410

411

412

413

paper, most of the specimens appear to have failed in the localised tearing mode depicted in Figure 4. However, one specimen, shown in Figs. 31 and 32 of their paper, failed in tilt bearing due to the bolt head punching through the connected sheet on the upstream side of the bolt hole. The S250 steel specimen, which had a bolt hole clearance of $1 \mathrm{~mm}$ on 8-mm bolt, is included in Table 10. Equation (9) was found to be about $10 \%$ conservative for this specimen.

Hoang et al. (2013) tested only one specimen, composed of 6082 T6 aluminium. Table 10 shows that Equation (9) was found to be accurate for this aluminium specimen, which had a bolt hole clearance of $0.5 \mathrm{~mm}$ on 8 -mm bolt.

\section{Oversized hole and oversized bolt head}

As indicated by the report's title, Yu \& Sheerah (2008) tested bolted connections with oversized and slotted holes. Equation (9) may not be applicable to connections with a hole diameter clearance significantly greater than $2 \mathrm{~mm}$ unless the bolt head size is commensurately larger.

For their specimens having a bolt hole clearance of $3.2 \mathrm{~mm}$ on $1 / 2$-inch $(12.7 \mathrm{~mm})$ bolt, two types of bolts were used, being A307 and A325 bolts. The A307 bolt had a measured head width $s$ of $18.8 \mathrm{~mm}$, comparable to that of the $12-\mathrm{mm}$ bolt used in the present tests considering the bolt diameters. Equation (9) is therefore not applicable to the specimens having a bolt hole clearance of $3.2 \mathrm{~mm}$ on A307 bolt. However, the A325 bolt had a measured head width $s$ of $21.9 \mathrm{~mm}$, which more than offset the enlarged hole clearance.

Table 11 lists the geometric dimensions and results of the specimens tested by Yu \& Sheerah (2008) which had a hole diameter clearance of $3.2 \mathrm{~mm}$ on A325 bolt and which failed in tilt bearing due to the bolt head punching through the connected sheet on the upstream side of the 
414

415

416

417

418

419

420

421

422

423

424

425

426

427

428

429

430

431

432

433

434

bolt hole. It can be seen that, in contrast to the code equations, Equation (9) is reasonably accurate for these specimens. In this case, the oversized bolt head offset the effect of the oversized bolt hole.

\section{Resistance factor (or capacity reduction factor)}

The mean professional factors $P_{\mathrm{m}}$ given by Equations (1), (2) and (9) for the 170 specimens listed in Tables 4 through 10 are given in Table 12, along with their coefficients of variation. The specimens with 3.2 mm hole clearance on A325 bolt, listed in Table 11, are not included in the present reliability analysis that is restricted to bolt holes with a maximum clearance of $2 \mathrm{~mm}$.

Section F1.1 of the North American specification (AISI 2012) specifies that the resistance factor $\phi$ of a design equation is determined as follows

$$
\phi=C_{\phi}\left(M_{m} F_{m} P_{m}\right) e^{p}
$$

in which $C_{\phi}$ is the calibration coefficient equal to 1.52 in the case of the Load and Resistance Factor Design (LRFD), $M_{\mathrm{m}}$ is the mean value of the material factor equal to 1.10 according to Table F1 of the North American specification, $F_{\mathrm{m}}$ is the mean value of the fabrication factor equal to 1.00 , and $P_{\mathrm{m}}$ is the mean value of the professional factor given in Table 12 for the concerned design equation.

The power $p$ of the natural logarithmic base $e$ in Equation (10) is

$$
p=-\beta_{0} \sqrt{V_{M}^{2}+V_{F}^{2}+C_{p} V_{P}^{2}+V_{Q}^{2}}
$$

in which $V_{M}$ is the coefficient of variation of the material factor equal to 0.08 in the present case, $V_{\mathrm{F}}$ is the coefficient of variation of the fabrication factor equal to $0.05, V_{\mathrm{P}}$ is the 
coefficient of variation of the professional factor given in Table 12 for the concerned design equation, $C_{\mathrm{p}}$ is the correction factor equal to 1.01 as computed from the relevant equation given in Section F1.1, and $V_{\mathrm{Q}}$ is the coefficient of variation of load effects equal to 0.21 as specified in Section F1.1.

It was found that in order to achieve the target reliability index $\beta_{0}$ of 3.5 in the LRFD, Equation (10) yields a resistance factor of 0.73 for the proposed Equation (9). Given the wide ranges of geometric and material variables included in the analysis, a resistance factor $\phi$ equal to 0.75 (rounded to the nearest 0.05) in conjunction with Equation (9) is therefore recommended for the LRFD approach for determining the ultimate tilt bearing capacity of a single-shear single-row bolted connection in flat steel sheets.

\section{Conclusions}

This paper has pointed out that the tilt bearing failure mode that may be experienced by a single-shear single-row bolted connection without washers is very distinct from the conventional bearing failure mode typical of a double-shear connection or a single-shear connection with washers. The tilt bearing failure is due to the bolt head and nut punching through the connected sheets on the upstream side of the respective bolt holes during tilting, while the conventional bearing failure takes place on the downstream side.

Unlike the conventional bearing capacity, it has been found that the tilt bearing capacity is not affected by the variation in material ductility of cold-reduced sheet steels. Furthermore, unlike other failure modes such as the net section tension fracture mode, fracture on the upstream side of one bolt hole only does not necessarily coincide with the maximum loadcarrying capacity of the single-shear bolted connection without washers. 
457 The paper has also pointed out that the tilt bearing failure mode is distinct from the localised 458 tearing mode, which may also be experienced by a single-shear bolted connection with or 459 without washers, and which was mistaken to be the net section tension fracture mode in the 460 past. The localised tearing mode appears to be more familiar to researchers in cold-formed 461 steel bolted connections.

462 This paper has presented the first systematic study on the tilt bearing capacities of singleshear single-row bolted connections, which were due to the bolt head and nut punching through the connected sheets on the upstream side of the respective bolt holes during tilting. It has been found that the tilt bearing capacity varies nonlinearly with the sheet thickness with an exponent equal to $4 / 3$, and is proportional to the square root of the bolt diameter. The proposed design equation includes the sheet width as a parameter of the tilt bearing capacity.

The proposed design equation is dimensionally consistent and is independent of the systems of measurement or dimensional units that may be used by the structural engineer. It has been found that the equation is reasonably accurate for 170 specimens tested by the authors and other researchers around the world, comprising specimens having sheet thicknesses ranging from $0.92 \mathrm{~mm}$ to $3.0 \mathrm{~mm}$ and bolt diameters ranging from $6.4 \mathrm{~mm}$ to $16 \mathrm{~mm}$ with hole 473 clearances ranging from $0.5 \mathrm{~mm}$ to $2.0 \mathrm{~mm}$. The tested ratios of sheet width to bolt diameter 474 W/d ranged from 3 to 16 . The accuracy of the proposed design equation has not been found to be significantly affected by the orientations of the bolt head and nut.

The equation has also been found to be reasonably accurate for specimens each having an oversized hole clearance of $3.2 \mathrm{~mm}$ when the A325 bolt type, which has an oversized head compared to the A307 bolt type, was used. 
479 It is recommended that a resistance factor of 0.75 be applied to the proposed design equation 480 in the LRFD approach of the North American specification for the design of cold-formed 481 steel structures.

\section{Acknowledgments}

483

484

485

486

487

488

489

490

491

492

493

494

495

496

497

498

499

500

The authors would like to thank the Australian Research Council for funding this research through the ARC Research Hub for Australian Steel Manufacturing under the Industrial Transformation Research Hubs scheme (Project ID: IH130100017). The authors would also like to thank Trevor Clayton and John Kralic, both of Bluescope, for supplying the steel materials used in the present work. All specimens were fabricated by Ritchie McLean. The G2 specimens were tested by Duncan Best with the assistance of Yufei Wu and Kealan Mulholland-Brown, two honours thesis students at the University of Wollongong.

\section{References}

AISI (2008) Test Methods for Mechanically Fastened Cold-Formed Steel Connections, ANSI/AISI S905-08, American Iron and Steel Institute, Washington, DC.

AISI (2012) The North American Specification for the Design of Cold-formed Steel Structural Members 2012 Edition, ANSI/AISI S100-12, American Iron and Steel Institute, Washington, DC.

Bryan, E. R. (1993) “The design of bolted joints in cold-formed steel sections.” Thin-Walled Struct., 16, 239-262.

Carril, J. L., LaBoube, R. A., and Yu, W. W. (1994) “Tensile and bearing capacities of bolted connections.” First Summary Report, Civil Engineering Study 94-1, University of Missouri-Rolla, Rolla, MO. 
501 Casafont, M., Arnedo, A., Roure, F., and Rodriguez-Ferran, A. (2006) "Experimental testing 502 of joints for seismic design of lightweight structures. Part 2: Bolted joints in straps.” 503 Thin-Walled Struct., 44, 677-691.

504 ECCS (2009) The Testing of Connections with Mechanical Fasteners in Steel Sheeting and 505 Sections, ECCS TC7 TWG 7.10, European Commission for Constructional Steelwork, $506 \quad$ Mem Martins, Portugal.

507

508

509

510

ECS (2006) Eurocode 3: Design of steel structures, Part 1-3: General rules - Supplementary rules for cold-formed members and sheeting, EN 1993-1-3:2006, European Committee for Standardisation, Brussels, Belgium.

Hancock, G. J. (2007) Design of Cold-Formed Steel Structures, $4^{\text {th }}$ ed., Australian Steel Institute, Sydney.

Hoang, T. D., Herbelot, C., Imad, A., and Benseddiq, N. (2013) “Numerical modelling for prediction of ductile fracture of bolted structure under tension shear loading.” Finite Elements in Analysis and Design, 67, 56-65.

LaBoube, R.A. (1988). "Strength of bolted connections: Is it bearing or net section?", Proc., $9^{\text {th }}$ Int. Specialty Conf. Cold-Formed Steel Structures, St Louis, MO, 589-601.

Rogers, C. A., and Hancock, G. J. (2000) "Failure modes of bolted-sheet-steel connections loaded in shear.” J. Struct. Eng., 126 (3), 288-296.

SA (2011) Continuous hot-dip metallic coated steel sheet and strip-Coatings of zinc and zinc alloyed with aluminium and magnesium, AS 1397-2011, Standards Australia, Sydney.

SA/SNZ (2005) Cold-Formed Steel Structures, AS/NZS 4600:2005, Standards Australia/Standards New Zealand, Sydney, Australia.

Talja, A., and Torkar, M. (2014) “Lap shear tests of bolted and screwed ferritic stainless steel connections.” Thin-Walled Struct., 83, 157-168. 
Teh, L. H., and Gilbert, B. P. (2012) "Net section tension capacity of bolted connections in cold-reduced steel sheets.” J. Struct. Eng., 138 (3), 337-344.

Teh, L. H., and Clements, D. D. A. (2012) "Block shear capacity of bolted connections in cold-reduced steel sheets,” J. Struct. Eng., 138 (4), 459-467.

Teh, L. H., and Uz, M. E. (2014) "Effect of loading direction on the bearing capacity of coldreduced sheet steels.” J. Struct. Eng., 140 (12), 06014005.

Teh, L. H. and Uz, M. E. (2015) "Ultimate shear-out capacity of structural steel bolted connections.” J. Struct. Eng., 141 (6), 04014152.

Yan, S., and Young, Y. B. (2011) “Tests of single-shear bolted connections of thin sheet steels at elevated temperatures.” Thin-Walled Struct., 49, 1320-1340.

Yan, S., and Young, Y. B. (2012) "Bearing factors for single shear bolted connections of thin sheet steels at elevated temperatures.” Thin-Walled Struct., 52, 126-142.

Yu, C., and Panyanouvong, M. X. (2013) "Bearing strength of cold-formed steel bolted connections with a gap.” Thin-Walled Struct., 67, 110-115.

Yu, C., and Sheerah, I. (2008) “Cold-formed Steel Bolted Connections Without Washers on Oversized and Slotted Holes.” Research Report RP08-11, Committee on Specifications for the Design of Cold-formed Steel Structural Members, American Iron and Steel Institute, Washington, DC.

Yu, W. W., and Mosby, R. L. (1981) “Bolted connections in cold-formed steel structures.” Final Report, Civil Engineering Study 81-1, University of Missouri-Rolla, Rolla, MO.

Wallace, J. A., and Schuster, R. M. (2001) “Testing of bolted cold formed steel connections in bearing (with and without washers).” Research Report RP01-4, Committee on Specifications for the Design of Cold-formed Steel Structural Members, American Iron and Steel Institute, Washington, DC. 
550 Wallace, J. A., and Schuster, R. M. (2002) "Calibration of bolted cold formed steel 551 connections in bearing (with and without washers).” Proc., $16^{\text {th }}$ Int. Specialty Conf. 552 Cold-Formed Steel Structures, Orlando, FL, 851-863. 


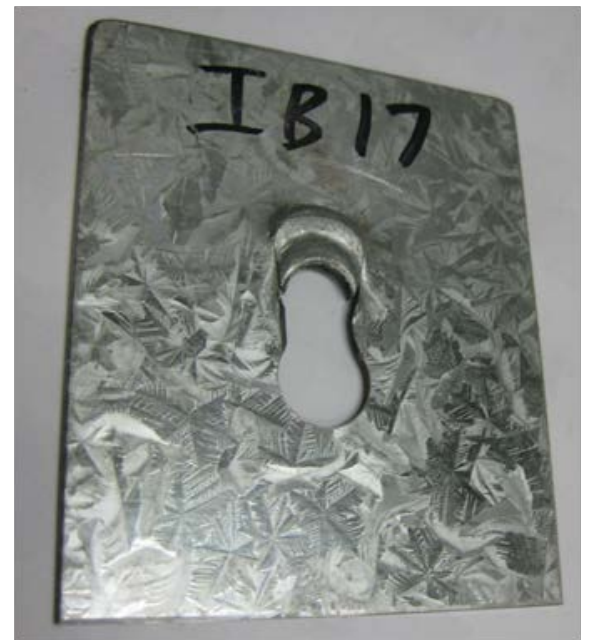

(a)

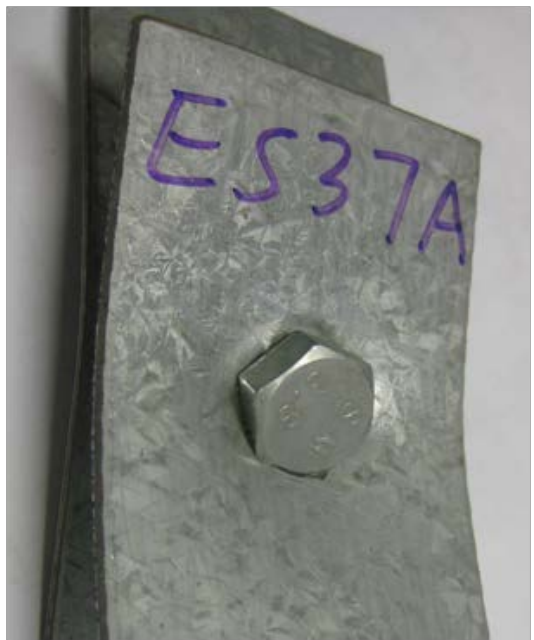

(b)

Figure 1 Distinct failure modes: (a) Bearing failure of a double-shear connection; (b) Tilt bearing failure of a single-shear connection 


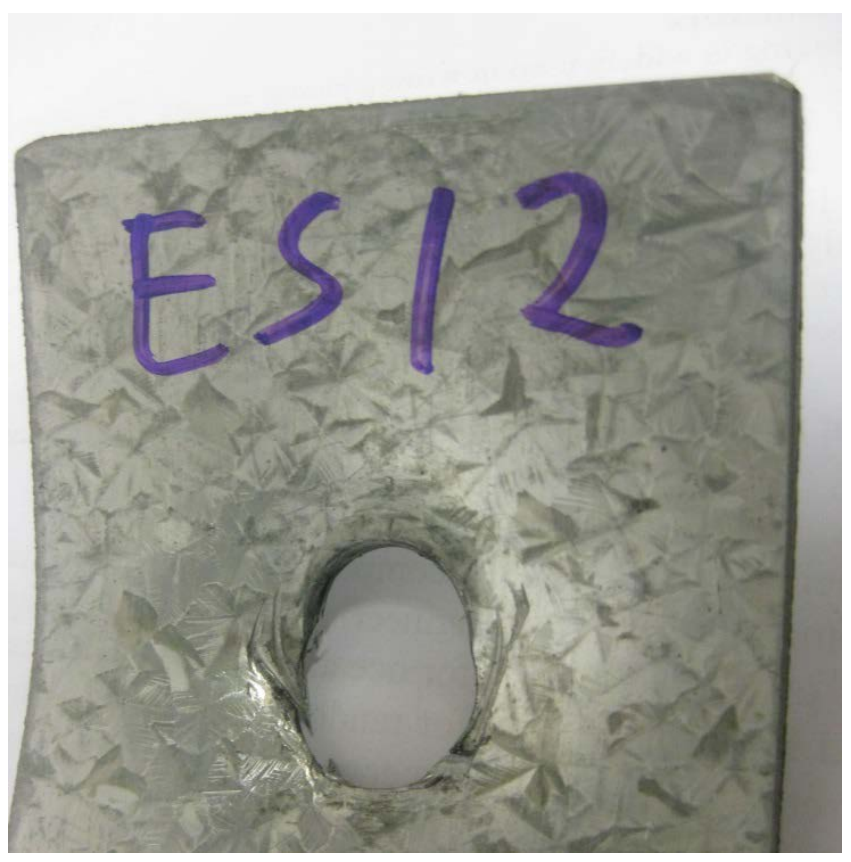

Figure 2 Fracture on the upstream side of bolt hole 

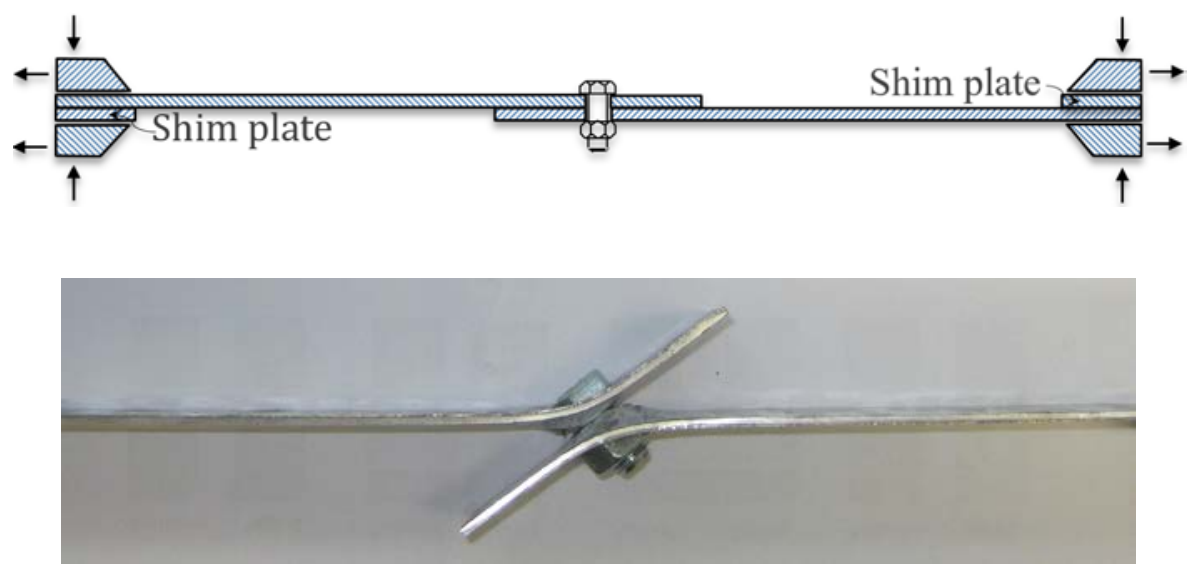

Figure 3 Tilting of a single-shear connection due to load eccentricity 


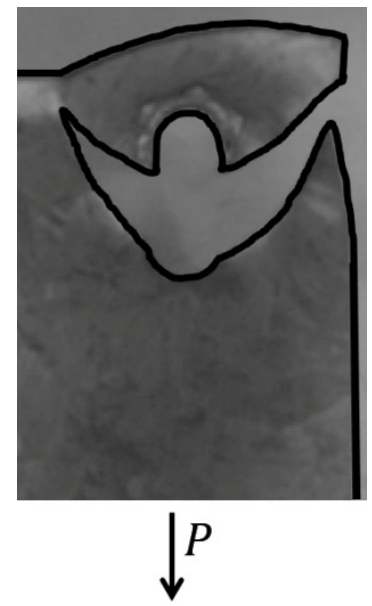

Figure 4 Localised tearing of a single-shear bolted connection (adapted from Casafont et al. 2006) 


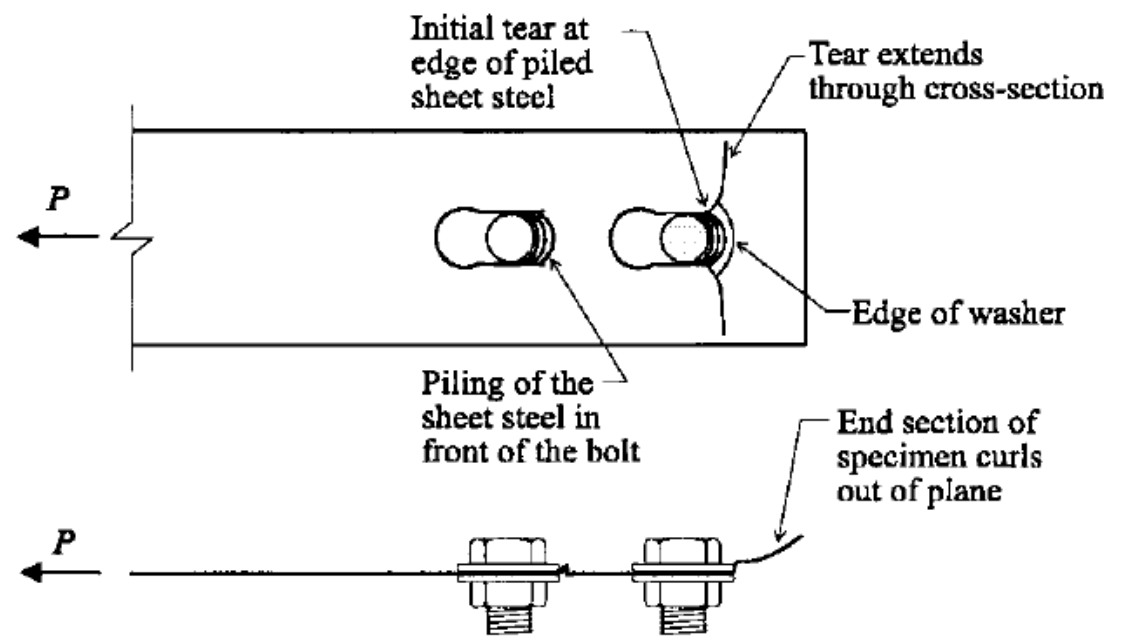

Figure 5 “Bearing with end curling” (Rogers \& Hancock 2000) 

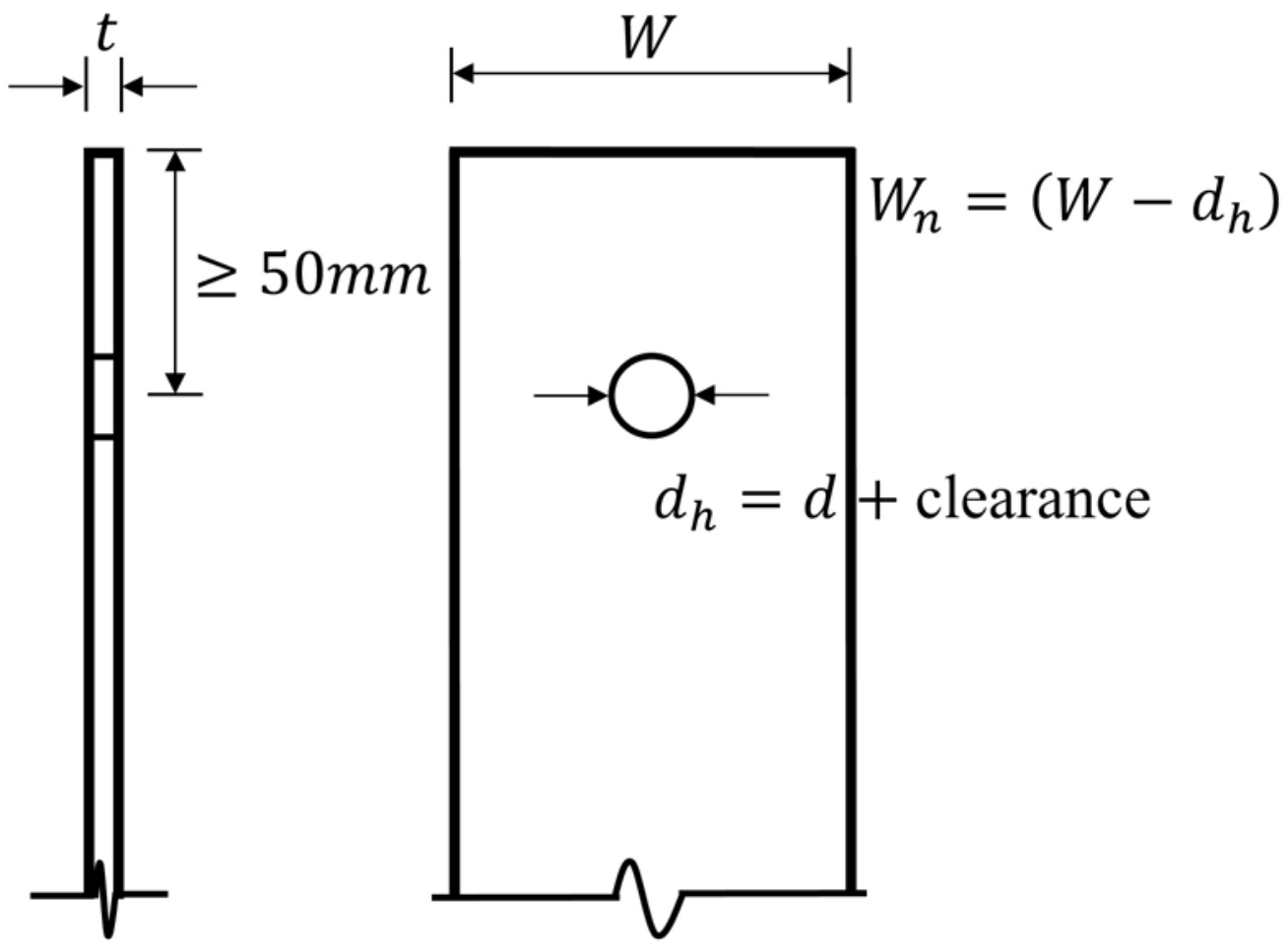

Figure 6 Geometric variables of single-bolt specimens 

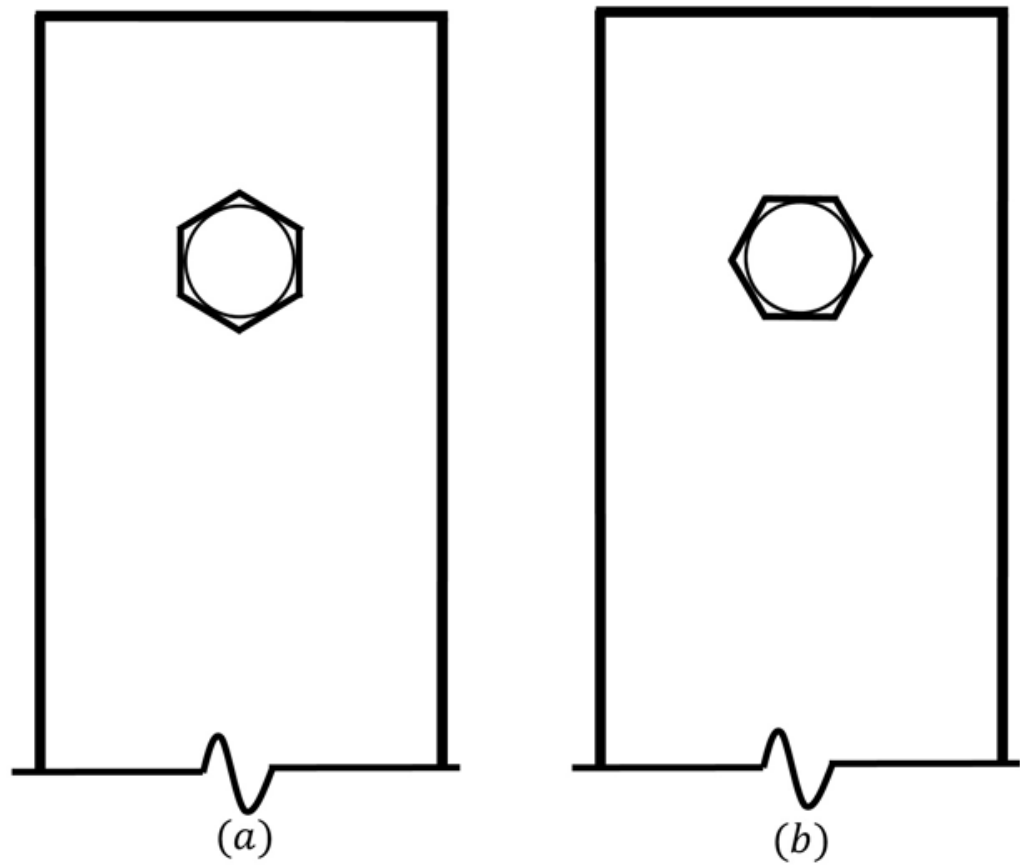

Figure 7 Two different orientations of bolt head and nut: (a) Orientation I; (b) Orientation II 


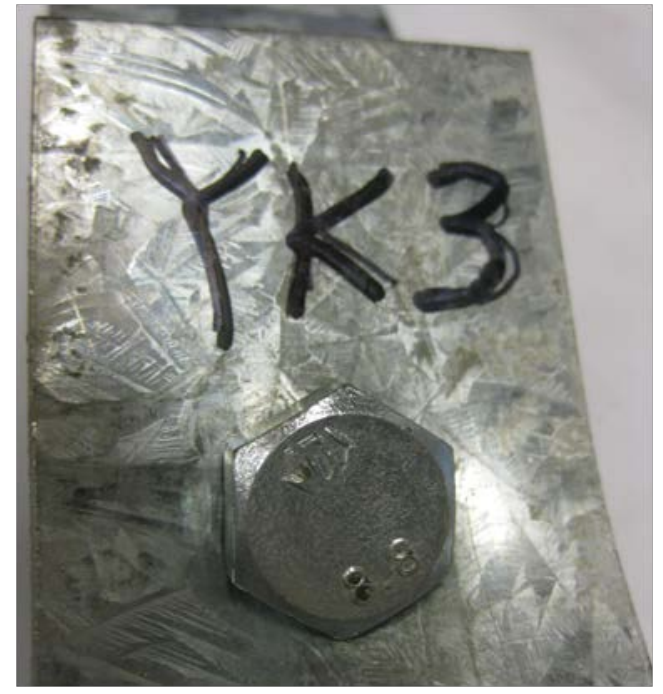

(a)

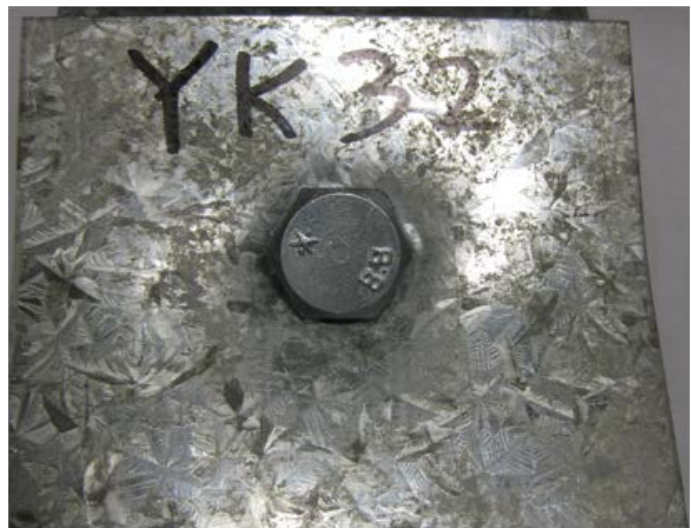

(b)

Figure 8 Specimens with bolt head (and nut) having (a) Orientation I; (b) Orientation II 


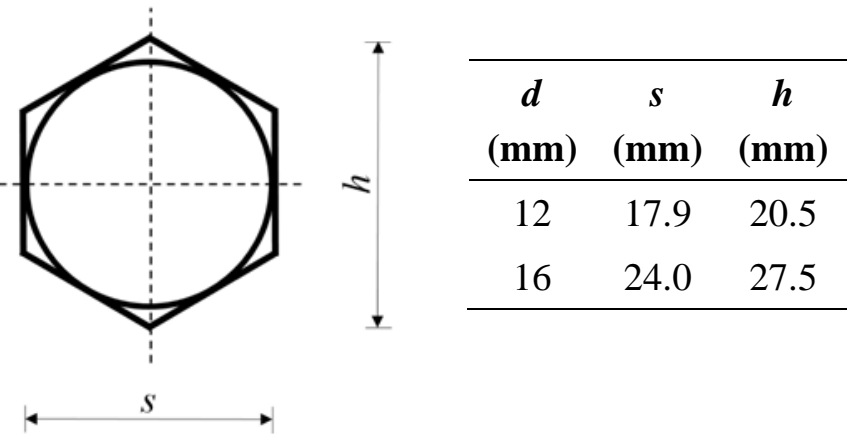

Figure 9 Measured dimensions of tested bolt heads 


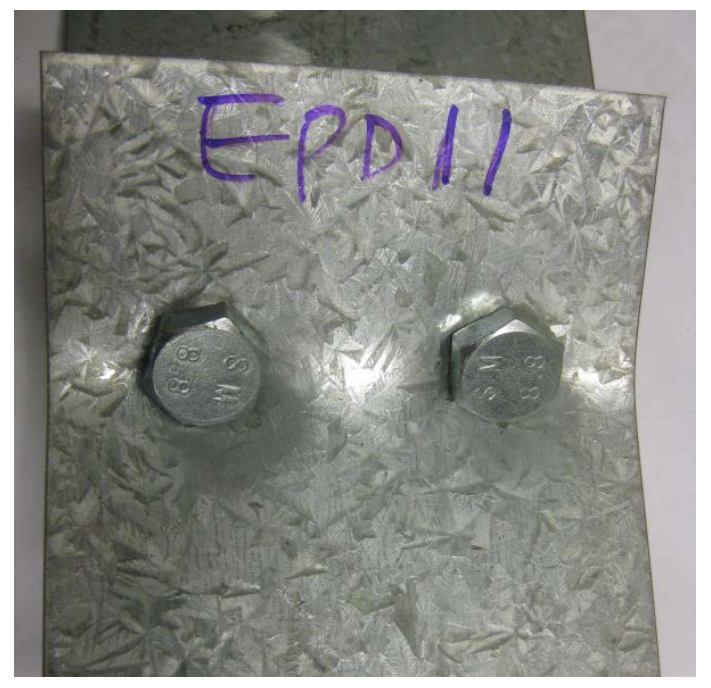

Figure 10 Single-shear single-row double bolted connection specimen 


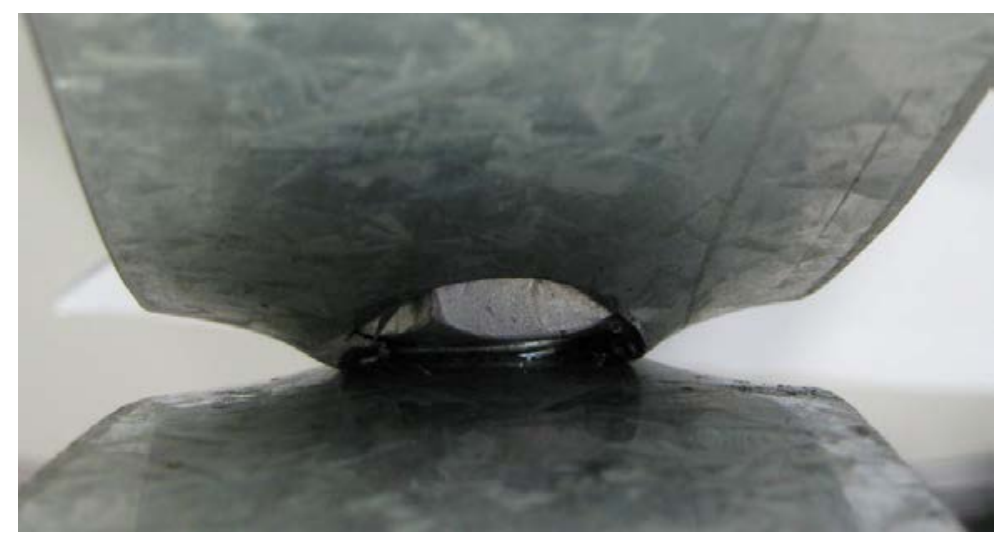

Figure 11 Bolt head punching through the bolt hole of Specimen ES34 


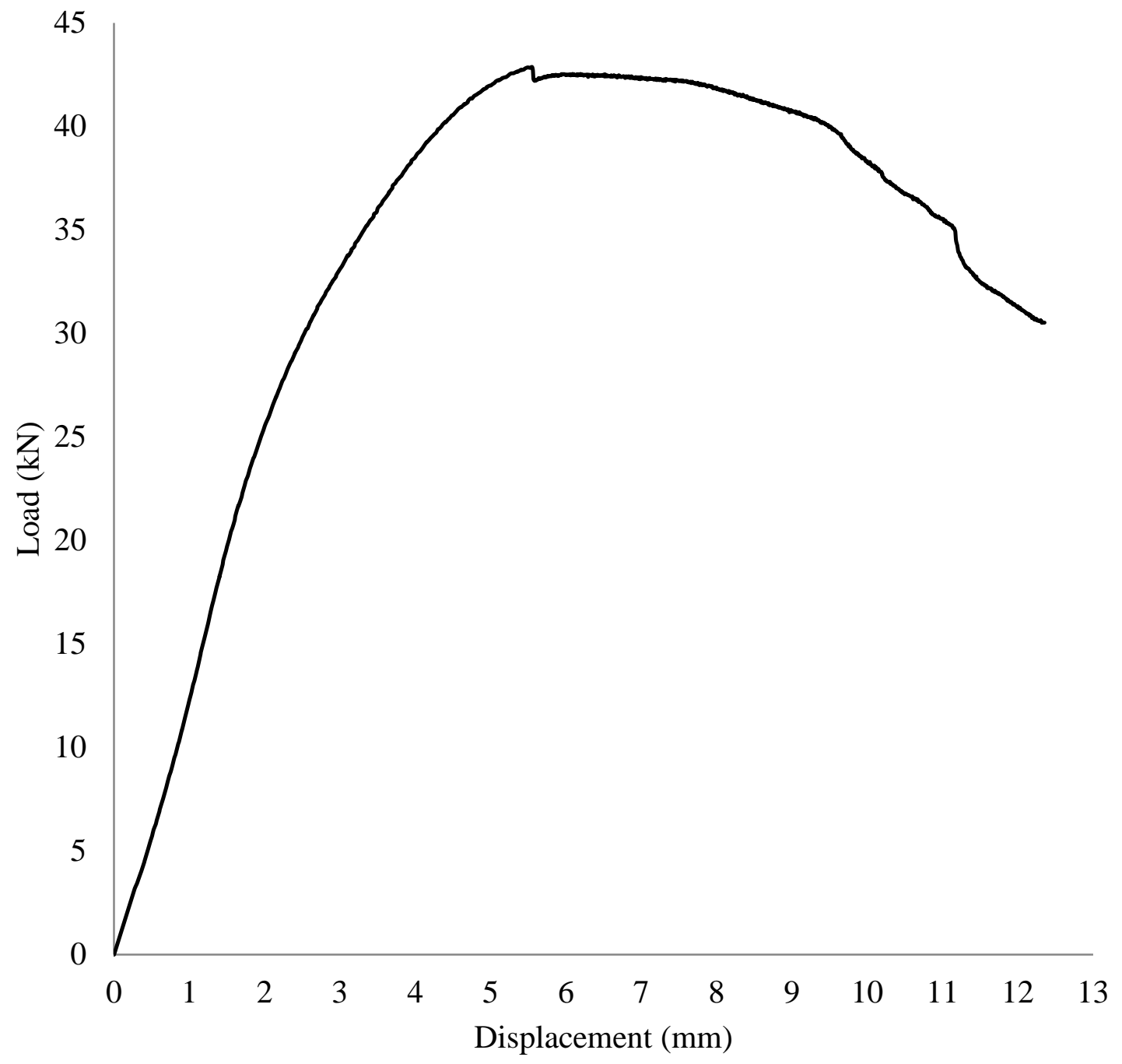

Figure 12 Load-displacement graph of Specimen ES34 


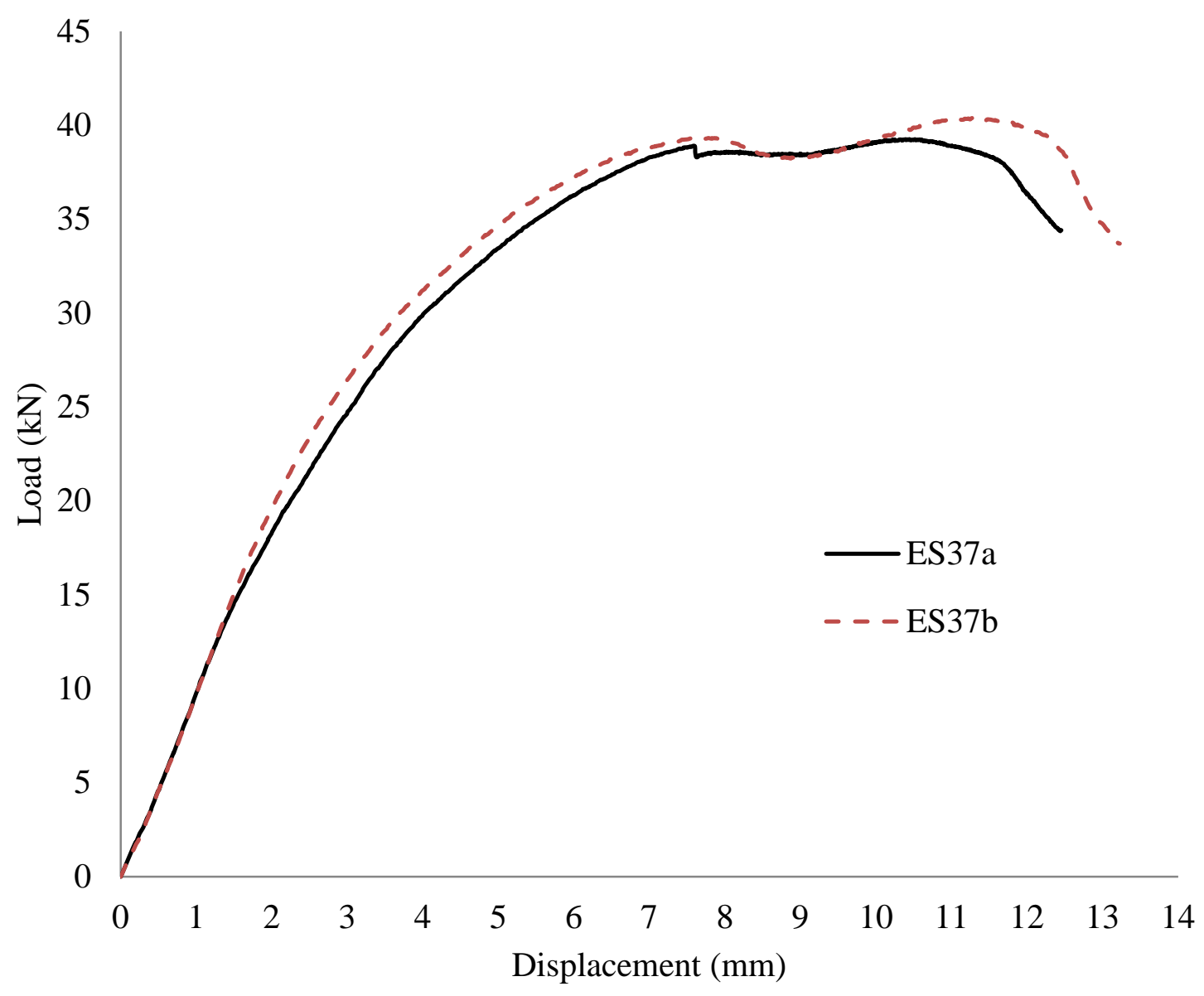

Figure 13 Load-displacement graphs of Specimens ES37a and ES37b 


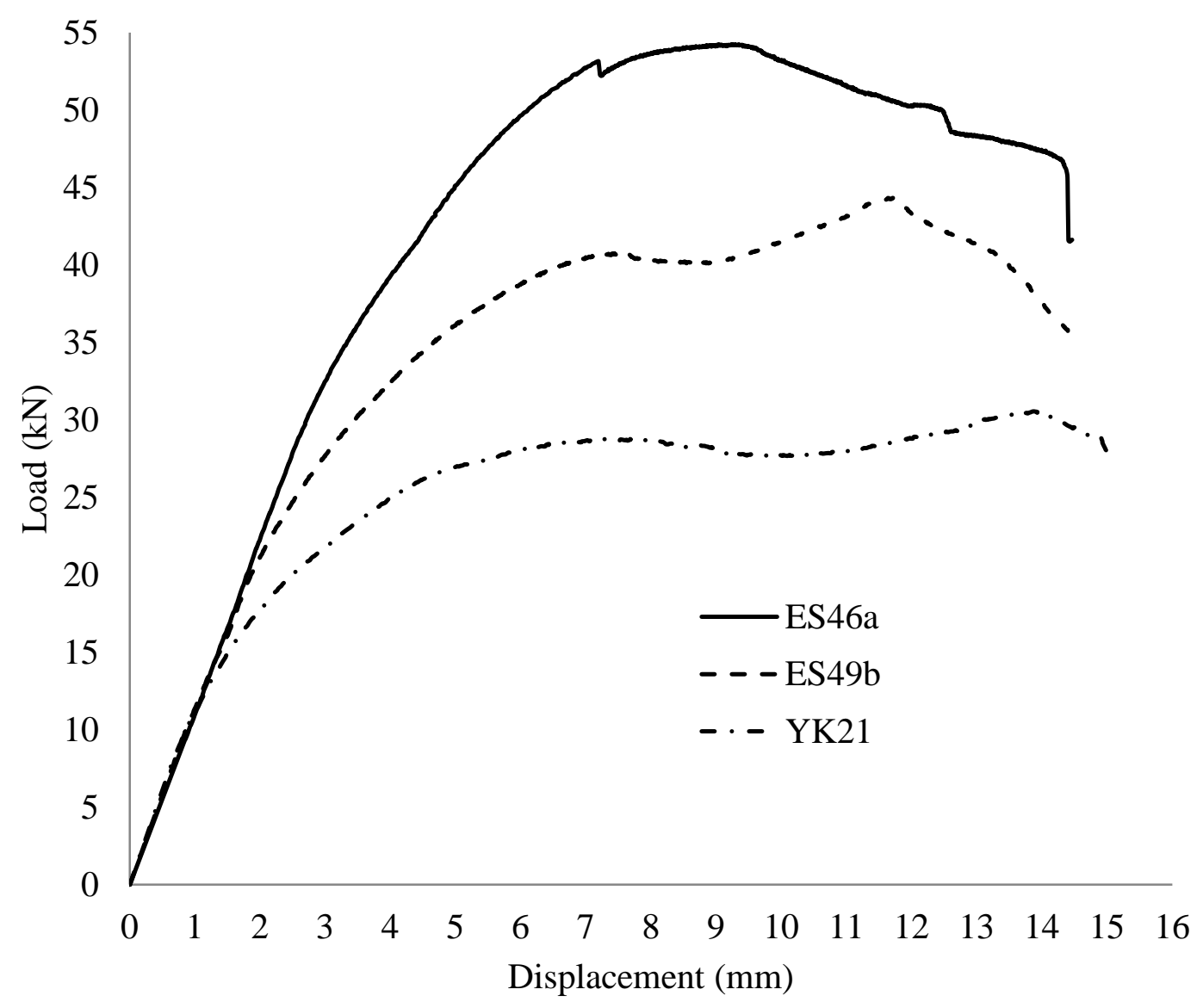

Figure 14 Load-displacement graphs of Specimens ES46a, ES49b and YK21 


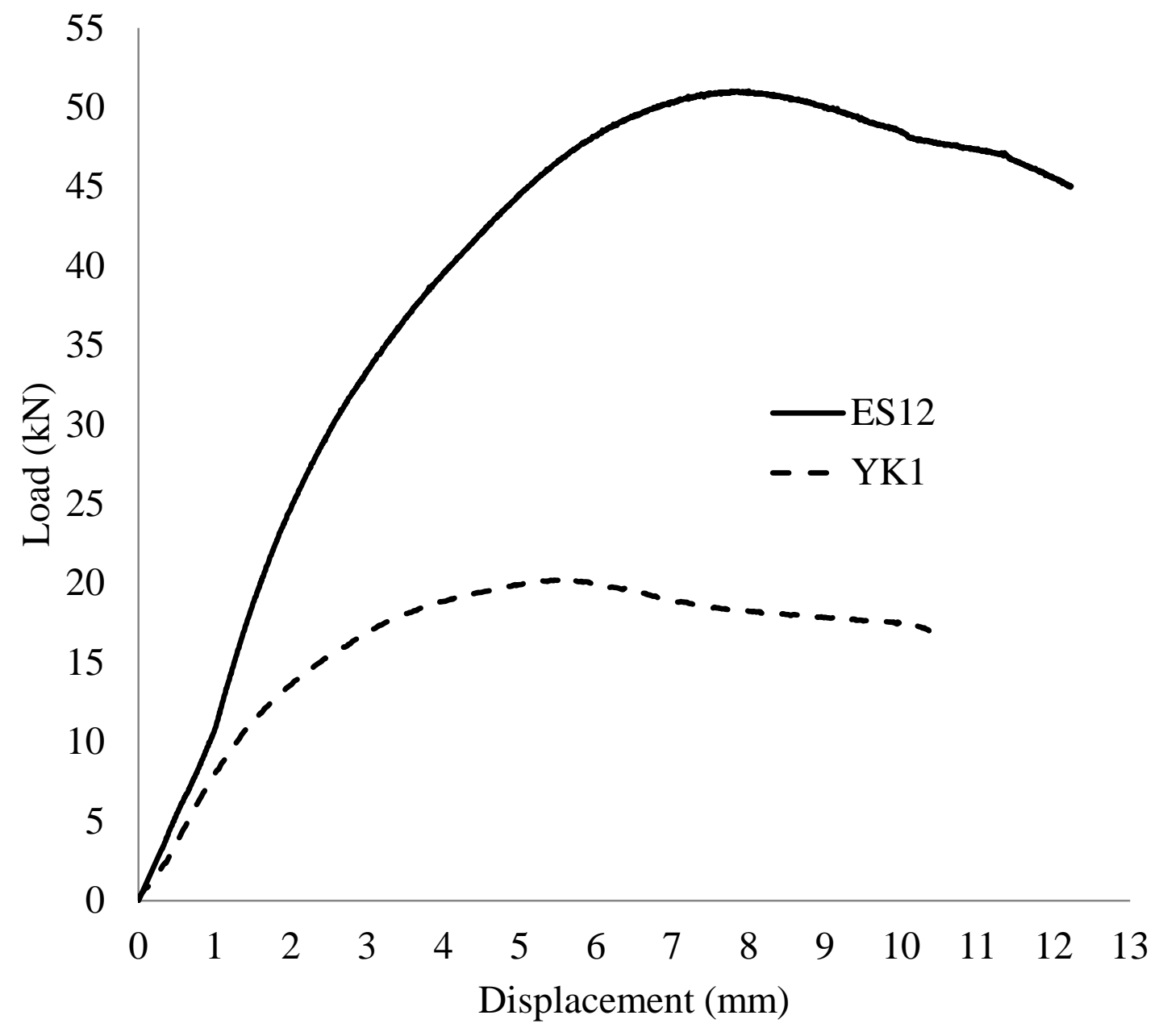

Figure 15 Load-displacement graphs of Specimens ES12 and YK1 


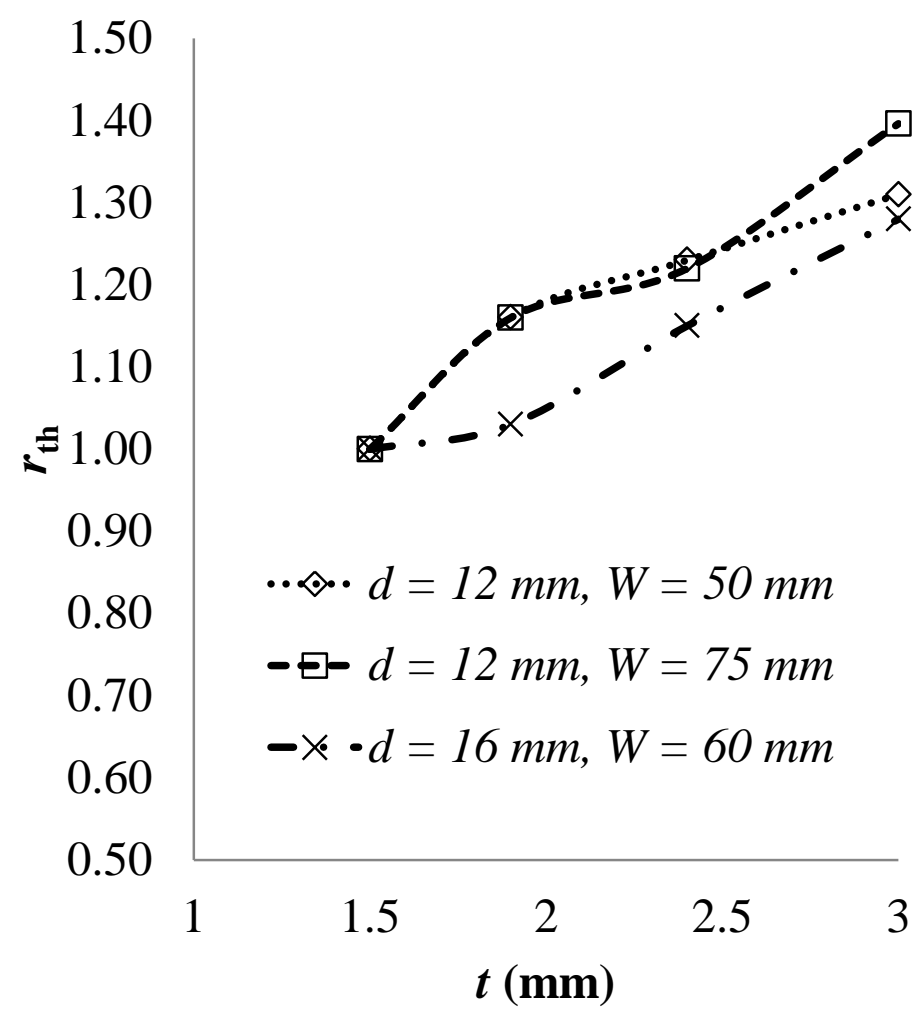

Figure 16 Exponential relationship between tilt bearing capacity and sheet thickness 
Table 1 Bearing factor $C$ in Section E3.3.1 (AISI 2012)

\begin{tabular}{cc}
\hline $\boldsymbol{d} / \boldsymbol{t}$ & $\boldsymbol{C}$ \\
\hline$<10$ & 3.0 \\
$10 \leq d / t \leq 22$ & $4-0.1 d / t$ \\
$>22$ & 1.8 \\
\hline
\end{tabular}

Table 2 Average material properties for G450 sheet steels

\begin{tabular}{|c|c|c|c|c|c|c|c|c|}
\hline & $\begin{array}{c}t_{\text {base }} \\
(\mathrm{mm})\end{array}$ & $\begin{array}{c}F_{\mathbf{y}} \\
(\mathbf{M P a})\end{array}$ & $\begin{array}{c}F_{\mathbf{u}} \\
(\mathbf{M P a})\end{array}$ & $\boldsymbol{F}_{\mathbf{u}} / \boldsymbol{F}_{\mathbf{y}}$ & $\begin{array}{c}\varepsilon 15 \\
(\%)\end{array}$ & $\begin{array}{c}\varepsilon 25 \\
(\%)\end{array}$ & $\begin{array}{c}\varepsilon_{50} \\
(\%)\end{array}$ & $\begin{array}{l}\varepsilon_{u 0} \\
(\%)\end{array}$ \\
\hline $1.5 \mathrm{~mm}$ & 1.48 & 555 & 590 & 1.06 & 21.5 & 16.3 & 12.0 & 6.9 \\
\hline $1.9 \mathrm{~mm}$ & 1.82 & 540 & 585 & 1.08 & 26.3 & 22.3 & 12.1 & 8.4 \\
\hline $2.4 \mathrm{~mm}$ & 2.36 & 535 & 580 & 1.08 & 31.0 & 23.8 & 16.3 & 8.9 \\
\hline $3.0 \mathrm{~mm}$ & 2.95 & 520 & 555 & 1.07 & 30.5 & 21.4 & 14.8 & 8.2 \\
\hline
\end{tabular}

Table 3 Average material properties for $\mathrm{G} 2$ sheet steels

\begin{tabular}{ccccccccc}
\hline & $\boldsymbol{t}_{\text {base }}$ & $\boldsymbol{F}_{\mathbf{y}}$ & $\boldsymbol{F}_{\mathbf{u}}$ & $\boldsymbol{F}_{\mathbf{u}} / \boldsymbol{F}_{\mathbf{y}}$ & $\boldsymbol{\boldsymbol { \varepsilon } _ { 1 5 }}$ & $\boldsymbol{\varepsilon}_{25}$ & $\boldsymbol{\varepsilon}_{50}$ & $\boldsymbol{\varepsilon}_{\mathbf{u o}}$ \\
& $\mathbf{( m m )}$ & $\mathbf{( M P a )}$ & $\mathbf{( M P a )}$ & & $\mathbf{( \% )}$ & $\mathbf{( \% )}$ & $\mathbf{( \% )}$ & $\mathbf{( \% )}$ \\
\hline $1.5 \mathrm{~mm}$ & 1.45 & 320 & 400 & 1.25 & 55.2 & 45.9 & 37.7 & 24.5 \\
$2.4 \mathrm{~mm}$ & 2.35 & 310 & 390 & 1.26 & 62.4 & 51.5 & 40.1 & 26.8 \\
\hline
\end{tabular}


Table 4 Results of G450 specimens having 12-mm bolt with 2-mm hole clearance

\begin{tabular}{|c|c|c|c|c|c|c|c|}
\hline \multirow{2}{*}{ Spec } & \multirow{2}{*}{$\begin{array}{c}W \\
(\mathbf{m m})\end{array}$} & \multirow{2}{*}{$\begin{array}{c}t \\
(\mathrm{~mm})\end{array}$} & \multirow[t]{2}{*}{$r_{\text {th }}$} & \multirow{2}{*}{$\begin{array}{c}P_{t} \\
(\mathbf{k N})\end{array}$} & \multicolumn{3}{|c|}{$\boldsymbol{P}_{\mathbf{t}} / \boldsymbol{P}_{\mathbf{p}}$} \\
\hline & & & & & (1) & (2) & (9) \\
\hline ES31 & 50 & 1.5 & Ref & 14.9 & 0.63 & 0.57 & 0.90 \\
\hline ES51 & & 1.9 & 1.16 & 21.0 & 0.73 & 0.66 & 0.97 \\
\hline ES53a & & 2.4 & 1.23 & 29.5 & 0.80 & 0.72 & 0.98 \\
\hline ES53b & & & & 28.0 & 0.76 & 0.68 & 0.92 \\
\hline ES33 & & 3.0 & 1.31 & 36.6 & 0.83 & 0.75 & 0.93 \\
\hline ES35 & 60 & 1.5 & Ref & 15.3 & 0.65 & 0.58 & 0.88 \\
\hline ES55a & & 1.9 & 1.18 & 22.6 & 0.79 & 0.71 & 1.00 \\
\hline ES55b & & & & 21.5 & 0.75 & 0.67 & 0.95 \\
\hline ES57a & & 2.4 & 1.19 & 31.6 & 0.86 & 0.77 & 1.00 \\
\hline ES57b & & & & 31.3 & 0.85 & 0.76 & 0.99 \\
\hline ES37a & & 3.0 & 1.39 & 39.3 & 0.89 & 0.80 & 0.96 \\
\hline ES37b & & & & 40.4 & 0.91 & 0.82 & 0.99 \\
\hline ES39 & 70 & 1.5 & Ref & 17.1 & 0.73 & 0.65 & 0.96 \\
\hline ES41 & & 3.0 & 1.38 & 44.3 & 1.00 & 0.90 & 1.05 \\
\hline ES47 & 75 & 1.5 & Ref & 17.5 & 0.74 & 0.67 & 0.97 \\
\hline ES59 & & 1.9 & 1.16 & 24.8 & 0.86 & 0.78 & 1.05 \\
\hline ES61a & & 2.4 & 1.22 & 33.7 & 0.91 & 0.82 & 1.02 \\
\hline ES61b & & & & 33.0 & 0.89 & 0.80 & 0.99 \\
\hline ES49a & & 3.0 & 1.40 & 47.3 & 1.07 & 0.96 & 1.10 \\
\hline ES49b & & & & 44.3 & 1.00 & 0.90 & 1.03 \\
\hline ES44 & 100 & 1.5 & Ref & 19.0 & 0.81 & 0.73 & 0.99 \\
\hline ES63a & & 1.9 & 1.08 & 24.8 & 0.86 & 0.78 & 0.99 \\
\hline ES63b & & & & 25.1 & 0.87 & 0.79 & 1.00 \\
\hline ES71 & & 2.4 & 1.13 & 33.8 & 0.91 & 0.82 & 0.96 \\
\hline ES70 & 120 & 1.9 & Ref & 24.9 & 0.87 & 0.78 & 0.96 \\
\hline ES69 & & 2.4 & 1.10 & 35.4 & 0.96 & 0.86 & 0.97 \\
\hline
\end{tabular}


Table 5 Results of G450 specimens having 16-mm bolt with 2-mm hole clearance

\begin{tabular}{|c|c|c|c|c|c|c|c|c|}
\hline \multirow{2}{*}{ Spec } & \multirow{2}{*}{$\begin{array}{c}W \\
(\mathbf{m m})\end{array}$} & \multirow{2}{*}{$\begin{array}{c}t \\
(\mathbf{m m})\end{array}$} & \multirow[t]{2}{*}{$r_{\text {th }}$} & \multirow[t]{2}{*}{$r_{d}$} & \multirow{2}{*}{$\begin{array}{c}P_{t} \\
(\mathbf{k N})\end{array}$} & \multicolumn{3}{|c|}{$\boldsymbol{P}_{\mathbf{t}} / \boldsymbol{P}_{\mathbf{p}}$} \\
\hline & & & & & & (1) & (2) & (9) \\
\hline ES32 & 50 & 1.5 & Ref & 1.17 & 17.4 & 0.57 & 0.50 & 0.92 \\
\hline ES52 & & 1.9 & 1.02 & 1.03 & 21.7 & 0.57 & 0.51 & 0.89 \\
\hline ES54a & & 2.4 & 1.16 & 1.10 & 32.3 & 0.66 & 0.59 & 0.94 \\
\hline ES54b & & & & & 30.9 & 0.63 & 0.56 & 0.90 \\
\hline ES34 & & 3.0 & 1.31 & 1.17 & 42.9 & 0.73 & 0.66 & 0.96 \\
\hline ES36 & 60 & 1.5 & Ref & 1.23 & 18.8 & 0.61 & 0.54 & 0.95 \\
\hline ES56 & & 1.9 & 1.03 & 1.07 & 23.5 & 0.61 & 0.55 & 0.91 \\
\hline ES58a & & 2.4 & 1.15 & 1.08 & 34.8 & 0.71 & 0.64 & 0.96 \\
\hline ES58b & & & & & 33.2 & 0.67 & 0.61 & 0.93 \\
\hline ES38 & & 3.0 & 1.28 & 1.13 & 45.1 & 0.77 & 0.69 & 0.97 \\
\hline ES40 & 70 & 1.5 & Ref & 1.18 & 20.2 & 0.66 & 0.58 & 0.99 \\
\hline ES42 & & 3.0 & 1.30 & 1.12 & 49.4 & 0.84 & 0.75 & 1.03 \\
\hline ES48a & 75 & 1.5 & Ref & 1.32 & 22.9 & 0.75 & 0.66 & 1.11 \\
\hline ES48b & & & & & 23.4 & 0.77 & 0.67 & 1.13 \\
\hline ES60 & & 1.9 & 0.99 & 1.13 & 28.0 & 0.73 & 0.66 & 1.04 \\
\hline ES62a & & 2.4 & 1.07 & 1.15 & 38.3 & 0.78 & 0.70 & 1.01 \\
\hline ES62b & & & & & 38.2 & 0.78 & 0.70 & 1.00 \\
\hline ES43 & & 3.0 & 1.21 & & 48.2 & 0.82 & 0.74 & 0.99 \\
\hline ES50 & & & & 1.17 & 51.9 & 0.88 & 0.79 & 1.06 \\
\hline ES45 & 100 & 1.5 & Ref & 1.33 & 25.2 & 0.82 & 0.72 & 1.14 \\
\hline ES64a & & 1.9 & 0.99 & 1.14 & 26.9 & 0.70 & 0.63 & 0.94 \\
\hline ES64b & & & & & 30.2 & 0.79 & 0.71 & 1.05 \\
\hline ES65a & & 2.4 & 1.08 & 1.18 & 40.2 & 0.82 & 0.73 & 1.00 \\
\hline ES65b & & & & & 39.4 & 0.80 & 0.72 & 0.98 \\
\hline ES46a & & 3.0 & 1.22 & N/A & 54.2 & 0.92 & 0.83 & 1.04 \\
\hline ES46b & & & & & 53.7 & 0.91 & 0.82 & 1.04 \\
\hline ES66a & 120 & 1.9 & Ref & 1.17 & 28.6 & 0.75 & 0.67 & 0.96 \\
\hline ES66b & & & & & 29.6 & 0.77 & 0.70 & 0.99 \\
\hline ES67a & & 2.4 & 1.13 & 1.21 & 43.1 & 0.87 & 0.79 & 1.03 \\
\hline ES67b & & & & & 42.7 & 0.87 & 0.78 & 1.02 \\
\hline ES68 & & 3.0 & 1.19 & N/A & 54.2 & 0.92 & 0.83 & 0.96 \\
\hline
\end{tabular}


Table 6 Results of G450 specimens with 1-mm hole clearance

\begin{tabular}{|c|c|c|c|c|c|c|c|}
\hline \multirow{2}{*}{ Spec } & \multirow{2}{*}{$\begin{array}{c}W \\
(\mathbf{m m})\end{array}$} & \multirow{2}{*}{$\begin{array}{c}t \\
(\mathrm{~mm})\end{array}$} & \multirow{2}{*}{$\begin{array}{c}d \\
(\mathrm{~mm})\end{array}$} & \multirow{2}{*}{$\begin{array}{c}P_{t} \\
(k N)\end{array}$} & \multicolumn{3}{|c|}{$\boldsymbol{P}_{\mathrm{t}} / \boldsymbol{P}_{\mathbf{p}}$} \\
\hline & & & & & (1) & (2) & (9) \\
\hline ES1a & 50 & 1.5 & 12 & 16.8 & 0.71 & 0.64 & 1.01 \\
\hline ES1b & & & & 17.0 & 0.72 & 0.65 & 1.01 \\
\hline ES2a & & & 16 & 19.1 & 0.62 & 0.55 & 1.01 \\
\hline ES2b & & & & 18.5 & 0.60 & 0.53 & 0.98 \\
\hline ES3a & & 3.0 & 12 & 39.8 & 0.90 & 0.81 & 1.01 \\
\hline ES3b & & & & 41.5 & 0.94 & 0.84 & 1.05 \\
\hline ES4a & & & 16 & 44.3 & 0.75 & 0.68 & 0.99 \\
\hline ES4b & & & & 42.5 & 0.72 & 0.65 & 0.95 \\
\hline ES5a & 60 & 1.5 & 12 & 17.2 & 0.73 & 0.66 & 0.99 \\
\hline ES5b & & & & 19.9 & 0.84 & 0.76 & 1.15 \\
\hline ES6a & & & 16 & 21.3 & 0.70 & 0.61 & 1.08 \\
\hline ES7a & & 3.0 & 12 & 39.8 & 0.90 & 0.81 & 0.97 \\
\hline ES7b & & & & 43.6 & 0.99 & 0.89 & 1.06 \\
\hline ES8a & & & 16 & 47.2 & 0.80 & 0.72 & 1.01 \\
\hline ES8b & & & & 47.1 & 0.80 & 0.72 & 1.01 \\
\hline ES9 & 70 & 1.5 & 12 & 18.2 & 0.77 & 0.69 & 1.01 \\
\hline ES10 & & & 16 & 23.5 & 0.77 & 0.67 & 1.15 \\
\hline ES11 & & 3.0 & 12 & 45.2 & 1.02 & 0.92 & 1.07 \\
\hline ES12 & & & 16 & 51.0 & 0.87 & 0.78 & 1.06 \\
\hline ES13 & 75 & 1.5 & 12 & 18.5 & 0.78 & 0.71 & 1.02 \\
\hline ES14 & & & 16 & 23.8 & 0.78 & 0.68 & 1.14 \\
\hline ES15 & & 3.0 & 12 & 44.8 & 1.01 & 0.91 & 1.04 \\
\hline ES16 & & & 16 & 54.6 & 0.93 & 0.83 & 1.12 \\
\hline ES17 & 100 & 1.5 & 12 & 19.2 & 0.81 & 0.73 & 1.00 \\
\hline ES18 & & & 16 & 24.6 & 0.80 & 0.70 & 1.12 \\
\hline ES19 & & 3.0 & 12 & 46.1 & 1.04 & 0.94 & 1.02 \\
\hline ES20 & & & 16 & 57.2 & 0.97 & 0.87 & 1.10 \\
\hline ES21 & 120 & 1.5 & & 24.3 & 0.79 & 0.70 & 1.06 \\
\hline ES22 & & 3.0 & & 57.4 & 0.97 & 0.88 & 1.06 \\
\hline
\end{tabular}


Table 7 Results of G2 specimens with 2-mm hole clearance

\begin{tabular}{|c|c|c|c|c|c|c|c|c|}
\hline \multirow{2}{*}{ Spec } & \multirow{2}{*}{$\begin{array}{c}W \\
(\mathrm{~mm})\end{array}$} & \multirow{2}{*}{$\begin{array}{c}t \\
(\mathrm{~mm})\end{array}$} & \multirow{2}{*}{$\begin{array}{c}d \\
(\mathrm{~mm})\end{array}$} & \multirow{2}{*}{ Orientation } & \multirow{2}{*}{$\begin{array}{c}P_{t} \\
(\mathbf{k N})\end{array}$} & \multicolumn{3}{|c|}{$\boldsymbol{P}_{\mathrm{t}} / \boldsymbol{P}_{\mathbf{p}}$} \\
\hline & & & & & & (1) & (2) & (9) \\
\hline YK35 & 50 & 1.5 & 12 & I & 10.8 & 0.69 & 0.62 & 0.98 \\
\hline YK36 & & & & II & 10.0 & 0.64 & 0.57 & 0.91 \\
\hline YK39 & & & 16 & I & 11.2 & 0.56 & 0.48 & 0.90 \\
\hline YK40 & & & & II & 11.2 & 0.55 & 0.48 & 0.90 \\
\hline YK43 & 75 & & 12 & I & 10.8 & 0.69 & 0.62 & 0.91 \\
\hline YK44 & & & & II & 10.8 & 0.69 & 0.62 & 0.90 \\
\hline YK47 & & & 16 & I & 13.2 & 0.66 & 0.57 & 0.97 \\
\hline YK48 & & & & II & 12.7 & 0.63 & 0.55 & 0.93 \\
\hline YK51 & 100 & & 12 & I & 12.9 & 0.83 & 0.74 & 1.02 \\
\hline YK52 & & & & II & 12.1 & 0.78 & 0.70 & 0.96 \\
\hline YK55 & & & 16 & I & 15.8 & 0.78 & 0.68 & 1.09 \\
\hline YK56 & & & & II & 14.9 & 0.74 & 0.64 & 1.02 \\
\hline YK59 & 120 & & 12 & I & 12.4 & 0.79 & 0.71 & 0.94 \\
\hline YK60 & & & & II & 10.4 & 0.66 & 0.60 & 0.79 \\
\hline YK63 & & & 16 & I & 15.0 & 0.75 & 0.65 & 1.00 \\
\hline YK64 & & & & II & 14.0 & 0.69 & 0.60 & 0.93 \\
\hline YK3 & 50 & 2.4 & 12 & I & 18.8 & 0.76 & 0.68 & 0.93 \\
\hline YK4 & & & & II & 18.2 & 0.73 & 0.66 & 0.90 \\
\hline YK7 & & & 16 & I & 19.9 & 0.60 & 0.54 & 0.87 \\
\hline YK8 & & & & II & 20.4 & 0.62 & 0.56 & 0.89 \\
\hline YK11 & 75 & & 12 & I & 22.2 & 0.90 & 0.81 & 1.00 \\
\hline YK12 & & & & II & 22.8 & 0.92 & 0.83 & 1.03 \\
\hline YK15 & & & 16 & I & 28.4 & 0.86 & 0.78 & 1.12 \\
\hline YK16 & & & & II & 26.3 & 0.80 & 0.72 & 1.04 \\
\hline YK19 & 100 & & 12 & I & 23.0 & 0.93 & 0.84 & 0.98 \\
\hline YK20 & & & & II & 23.2 & 0.94 & 0.84 & 0.99 \\
\hline YK23 & & & 16 & I & 29.9 & 0.91 & 0.82 & 1.11 \\
\hline YK24 & & & & II & 28.0 & 0.85 & 0.76 & 1.04 \\
\hline YK27 & 120 & & 12 & I & 23.2 & 0.94 & 0.84 & 0.95 \\
\hline YK28 & & & & II & 23.6 & 0.95 & 0.86 & 0.97 \\
\hline YK31 & & & 16 & I & 29.3 & 0.89 & 0.80 & 1.05 \\
\hline YK32 & & & & II & 24.7 & 0.75 & 0.67 & 0.88 \\
\hline
\end{tabular}


Table 8 Results of G2 specimens with 1-mm hole clearance

\begin{tabular}{|c|c|c|c|c|c|c|c|c|}
\hline \multirow{2}{*}{ Spec } & \multirow{2}{*}{$\begin{array}{c}W \\
(\mathbf{m m})\end{array}$} & \multirow{2}{*}{$\begin{array}{c}t \\
(\mathrm{~mm})\end{array}$} & \multirow{2}{*}{$\begin{array}{c}d \\
(\mathrm{~mm})\end{array}$} & \multirow{2}{*}{ Orientation } & \multirow{2}{*}{$\begin{array}{c}P_{t} \\
(\mathbf{k N})\end{array}$} & \multicolumn{3}{|c|}{$\boldsymbol{P}_{\mathrm{t}} / \boldsymbol{P}_{\mathbf{p}}$} \\
\hline & & & & & & (1) & (2) & (9) \\
\hline YK33 & 50 & 1.5 & 12 & I & 10.4 & 0.66 & 0.60 & 0.94 \\
\hline YK34 & & & & II & 10.7 & 0.69 & 0.62 & 0.98 \\
\hline YK37 & & & 16 & I & 10.5 & 0.52 & 0.45 & 0.84 \\
\hline YK38 & & & & II & 13.3 & 0.66 & 0.57 & 1.07 \\
\hline YK41 & 75 & & 12 & I & 13.9 & 0.89 & 0.80 & 1.16 \\
\hline YK42 & & & & II & 12.0 & 0.77 & 0.69 & 1.00 \\
\hline YK45 & & & 16 & I & 15.3 & 0.76 & 0.66 & 1.11 \\
\hline YK46 & & & & II & 15.7 & 0.78 & 0.68 & 1.15 \\
\hline YK49 & 100 & & 12 & I & 14.2 & 0.91 & 0.82 & 1.12 \\
\hline YK50 & & & & II & 14.5 & 0.93 & 0.84 & 1.15 \\
\hline YK53 & & & 16 & I & 13.5 & 0.67 & 0.58 & 0.93 \\
\hline YK54 & & & & II & 16.8 & 0.83 & 0.72 & 1.15 \\
\hline YK57 & 120 & & 12 & I & 13.9 & 0.89 & 0.80 & 1.06 \\
\hline YK58 & & & & II & 13.9 & 0.89 & 0.80 & 1.06 \\
\hline YK61 & & & 16 & I & 16.5 & 0.82 & 0.71 & 1.10 \\
\hline YK62 & & & & II & 15.0 & 0.75 & 0.65 & 1.00 \\
\hline YK1 & 50 & 2.4 & 12 & I & 20.3 & 0.82 & 0.74 & 0.99 \\
\hline YK2 & & & & II & 19.9 & 0.80 & 0.72 & 0.97 \\
\hline YK5 & & & 16 & I & 20.4 & 0.62 & 0.56 & 0.88 \\
\hline YK6 & & & & II & 19.7 & 0.60 & 0.54 & 0.85 \\
\hline YK9 & 75 & & 12 & I & 24.9 & 1.02 & 0.92 & 1.13 \\
\hline YK10 & & & & II & 23.7 & 0.96 & 0.86 & 1.07 \\
\hline YK13 & & & 16 & I & 27.1 & 0.82 & 0.74 & 1.06 \\
\hline YK14 & & & & II & 28.1 & 0.85 & 0.77 & 1.11 \\
\hline YK17 & 100 & & 12 & I & 25.1 & 1.02 & 0.91 & 1.07 \\
\hline YK18 & & & & II & 24.5 & 0.99 & 0.89 & 1.04 \\
\hline YK21 & & & 16 & I & 30.6 & 0.93 & 0.83 & 1.13 \\
\hline YK22 & & & & II & 29.3 & 0.89 & 0.80 & 1.09 \\
\hline YK25 & 120 & & 12 & I & 25.3 & 1.02 & 0.92 & 1.04 \\
\hline YK26 & & & & II & 25.4 & 1.02 & 0.92 & 1.04 \\
\hline YK29 & & & 16 & I & 30.6 & 0.93 & 0.84 & 1.10 \\
\hline YK30 & & & & II & 30.6 & 0.93 & 0.83 & 1.09 \\
\hline
\end{tabular}


Table 9 Results of single-shear single-row double bolted connections

\begin{tabular}{|c|c|c|c|c|c|c|c|}
\hline \multirow{2}{*}{ Spec } & \multirow{2}{*}{$\begin{array}{c}W \\
(\mathbf{m m})\end{array}$} & \multirow{2}{*}{$\begin{array}{c}t \\
(\mathrm{~mm})\end{array}$} & \multirow{2}{*}{$\begin{array}{c}d \\
(\mathrm{~mm})\end{array}$} & \multirow{2}{*}{$\begin{array}{c}P_{\mathbf{t}} \\
(\mathbf{k N})\end{array}$} & \multicolumn{3}{|c|}{$\boldsymbol{P}_{\mathbf{t}} / \boldsymbol{P}_{\mathbf{p}}$} \\
\hline & & & & & (1) & (2) & (9) \\
\hline EPD5 & 75 & 1.5 & 12 & 31.5 & 0.67 & 0.60 & 1.01 \\
\hline EPD9a & 100 & & & 34.0 & 0.72 & 0.65 & 1.02 \\
\hline EPD9b & & & & 35.2 & 0.75 & 0.67 & 1.06 \\
\hline EPD10 & & & 16 & 41.9 & 0.68 & 0.60 & 1.11 \\
\hline EPD11 & & 3.0 & 12 & 76.7 & 0.87 & 0.78 & 0.97 \\
\hline EPD12 & & & 16 & 86.3 & 0.73 & 0.66 & 0.97 \\
\hline
\end{tabular}

Table 10 Results of independent researchers

\begin{tabular}{|c|c|c|c|c|c|c|c|c|}
\hline \multirow{2}{*}{ Researchers } & \multirow{2}{*}{$\begin{array}{c}W \\
(\mathrm{~mm})\end{array}$} & \multirow{2}{*}{$\begin{array}{c}t \\
(\mathrm{~mm})\end{array}$} & \multirow{2}{*}{$\begin{array}{c}d \\
(\mathrm{~mm})\end{array}$} & \multirow{2}{*}{$\begin{array}{c}F_{u} \\
(\mathrm{MPa})\end{array}$} & \multirow{2}{*}{$\begin{array}{c}P_{t} \\
(k N)\end{array}$} & \multicolumn{3}{|c|}{$\boldsymbol{P}_{\mathbf{t}} / \boldsymbol{P}_{\mathbf{p}}$} \\
\hline & & & & & & (1) & (2) & (9) \\
\hline \multirow{12}{*}{ Yu \& Sheerah (2008) } & 101.6 & 0.92 & 6.4 & 375 & 5.18 & 1.06 & 0.96 & 1.09 \\
\hline & & & & & 5.40 & 1.11 & 1.00 & 1.14 \\
\hline & & & & & 5.09 & 1.04 & 0.94 & 1.07 \\
\hline & & & & & 5.48 & 1.12 & 1.01 & 1.15 \\
\hline & & & & & 5.02 & 1.03 & 0.93 & 1.06 \\
\hline & & & & & 5.05 & 1.04 & 0.93 & 1.06 \\
\hline & & 1.12 & & 485 & 8.16 & 1.06 & 0.95 & 1.02 \\
\hline & & & & & 8.42 & 1.09 & 0.98 & 1.05 \\
\hline & & & & & 8.12 & 1.05 & 0.95 & 1.02 \\
\hline & & & & & 7.67 & 0.99 & 0.89 & 0.96 \\
\hline & & & & & 7.96 & 1.03 & 0.93 & 1.00 \\
\hline & & & & & 8.11 & 1.05 & 0.94 & 1.01 \\
\hline${ }^{\mathrm{a} C}$ Casafont et al. (2006) & 100 & 1.58 & 8 & 390 & 21.9 & 0.98 & 0.88 & 1.11 \\
\hline Hoang et al. (2013) & 42.5 & 2.00 & & 365 & 12.3 & 0.93 & 0.84 & 0.99 \\
\hline
\end{tabular}


Table 11 Results for Yu \& Sheerah (2008)'s specimens with $3.2 \mathrm{~mm}$ clearance on A325 bolt (oversized head)

\begin{tabular}{|c|c|c|c|c|c|c|c|}
\hline \multirow{2}{*}{$\begin{array}{c}W \\
(\mathrm{~mm})\end{array}$} & \multirow{2}{*}{$\begin{array}{c}t \\
(\mathrm{~mm})\end{array}$} & \multirow{2}{*}{$\begin{array}{c}d \\
(\mathrm{~mm})\end{array}$} & \multirow{2}{*}{$\begin{array}{c}F_{u} \\
(\mathbf{M P a})\end{array}$} & \multirow{2}{*}{$\begin{array}{c}P_{t} \\
(\mathbf{k N})\end{array}$} & \multicolumn{3}{|c|}{$\boldsymbol{P}_{\mathbf{t}} / \boldsymbol{P}_{\mathbf{p}}$} \\
\hline & & & & & (1) & (2) & (9) \\
\hline \multirow[t]{3}{*}{101.6} & 1.75 & 12.7 & 480 & 20.8 & 0.87 & 0.78 & 1.03 \\
\hline & & & & 22.0 & 0.91 & 0.82 & 1.09 \\
\hline & & & & 20.7 & 0.86 & 0.77 & 1.03 \\
\hline
\end{tabular}

Table 12 Performance of alternative equations for 170 specimens

\begin{tabular}{lccc}
\hline & Eqn (1), AISI (2012) & Eqn (2), ECS (2006) & Eqn (9), Proposed \\
\hline $\boldsymbol{P}_{\mathrm{m}}$ & 0.82 & 0.74 & 1.01 \\
\hline COV & 0.162 & 0.187 & 0.073 \\
\hline
\end{tabular}

